\title{
A Pioneering Career in Electrochemistry: Jean-Michel Savéant
}

\author{
Cyrille Costentin ${ }^{a, b}$, Benoît Limoges ${ }^{c}$, Marc Robert $c, d$, and Cédric Tard $e$
}

${ }^{a}$ Département de Chimie Moléculaire, Université Grenoble-Alpes, CNRS, UMR 5250, 38000 Grenoble, France. ${ }^{b}$ Université de Paris, F-75013 Paris, France. ${ }^{c}$ Université de Paris, Laboratoire d'Electrochimie Moléculaire, CNRS, UMR 7591, F-75013 Paris, France. ${ }^{d}$ Institut Universitaire de France (IUF), F-75005 Paris, France. ${ }^{e}$ Laboratoire de Chimie Moléculaire, Ecole Polytechnique, CNRS, IP Paris, 91128 Palaiseau, France

\begin{abstract}
Prof. Jean-Michel Savéant sadly passed on August 16 2020. We would like to honor his memory, his tremendous contribution to electrochemistry and its use for a general understanding of the laws of physical chemistry. In this review, we highlight his decisive role in the foundation of molecular electrochemistry. We also present his major achievements in the field of molecular and biomolecular catalysis. Finally, we review his unique contribution to dissociative electron transfers and to the electrochemical approach of proton-coupled electron transfers. This shows how various concepts rigorously established and experimentally validated assemble to each other to enlighten complex systems.
\end{abstract}

\section{Introduction}

Molecular electrochemistry is a "segment of electrochemistry where attention is primarily focused on the molecular changes brought about by electron transfer to or from an electrode." Thus defined, it is immediately evident that molecular electrochemistry can be an extraordinary tool to investigate many aspects of molecular reactivity and irrigates many fields of chemistry and biochemistry. Prof. J-M. Savéant, who sadly passed on August 162020 dedicated his long carrier to develop, conceptualize and use molecular electrochemistry. It is not possible to mention all contributions of J-M. Savéant who published almost 500 papers. We will thus focus on a few salient contributions with particular emphasis to the field of catalysis.

Born in Brittany in 1933, Jean-Michel Savéant received his education at Ecole Normale Supérieure in Paris where he was laureate of the "Agregation de Sciences Physiques". After a pre-doctoral stay at the Istituto di Chimica Fisica dell' Università di Padova in 1959, where he met Prof. Elio Vianello, he served two years (1960-62) as Officer in the French Marine for his Military Service. He then returned to Ecole Normale Supérieure where he received his Docteures-Sciences Physiques (PhD) in 1966. He was then AgrégéPréparateur and the Vice-Director of the Laboratoire de Chimie of the same school, leading an electrochemistry group. In 1971 he moved with his group to the newly created Université Paris 7 (now Université de Paris) where he established the Laboratoire d'Electrochimie later named Laboratoire d'Electrochimie Moléculaire in 1988. He was professor until 1985 when he became Directeur de Recherche at CNRS and then kept this position as a CNRS emeritus. Recognized as a great scientist, he was elected both at the French Académie des Sciences (2000) and as a Foreign Associate of the National Acadamy of Science of the USA (2001). With his strong personality, J-M. Savéant was often both admired and feared for his intransigence toward scientific rigor. Along his career, he developed strong interaction with scientists across the world, in particular in Italy a country that he was in love with and admires the culture and languages, being able to speak fluently Italian as well as Venetian dialect. He also developed scientific and friendly relationships in the US, in particular with Fred Anson at Caltech where he was invited Professor in 1988-89 as a Sherman Fairchild Distinguished Scholar, and with Allen J. Bard at the University of Texas who was on sabbatical in J-M Savéant's lab in 1973. He received many awards among them the Bruno Beyer Award of the Royal Australian Chemistry Institute (2005), ECS Organic and Biological Electrochemistry Division Manuel M. Baizer Award (2002), the ECS Olin Palladium Award (1993), and Faraday Medal of the Royal Chemical Society (1983). He was Oskar K. Rice Distinguished Lecturer at the University of North Carolina, Chapel Hill (1995), Nelson Leonard Distinguished Lecturer at the University of Illinois (1999), and George Fisher Baker Lecturer at Cornell University (2002). This was the occasion to write his book "Elements of Molecular and Biomolecular Electrochemistry". ${ }^{1}$

\section{Foundation of Molecular Electrochemistry}

J-M. Savéant started his career at a time where analytical electrochemistry was dominated by aqueous electrochemistry and polarography as the most popular analytical technique. The development of a new technique, e.g. cyclic voltammetry (CV), was at its infancy but he quickly realized that it could be a very powerful tool to study both interfacial electron transfers and chemical reactions associated to/triggered by electron transfer. At the same time, electrochemistry in organic solvents got more common, thus giving rise to new opportunities to use electrochemistry for studying organic reactions and/or perform organic electrochemistry, i.e. organic transformations triggered by interfacial electron transfer. However, there were at least two requirements for the development of the use of cyclic voltammetry as a technique to investigate reactions: one was the development of suitable instrumentation, i.e. potentiostat with fast enough operational amplifiers, and the other was the development of a formal framework to analyze CVs. The contribution of J-M. Savéant in the later is now widely recognized and it was actually acknowledged from the very beginning (together with his collaborator and dear friend Elio Vianello ${ }^{2}$ ) as indicated by the following quotation of Nicholson and Shain in their famous 1964 Anal. Chem. paper (Theory of Stationary Electrode Polar- 
ography): "Savéant and Vianello developed the theory for the catalytic mechanism, the preceding chemical reaction, and also have discussed the case involving a very rapid reaction following the charge transfer" ${ }^{3}$ From their fruitful collaboration initiated during the pre-doctoral stay of J-M Savéant in Padova, J-M. Savéant and E. Vianello published in 1967 a seminal paper on the general theory for the calculation of voltammetric wave corresponding to a chemical reaction of any order, preceding, following or parallel to an electron transfer. ${ }^{4}$ It can be considered as an important piece in the foundation of molecular electrochemistry. At the same time, experimental studies were undergone by the first students mentored by J-M. Savéant, Claude Andrieux and Louis Nadjo,5,6 and it appeared that considering mechanisms involving more than one electron transfer was also mandatory. Then the famous $\boldsymbol{E C E} / \boldsymbol{D I S P}$ mechanism (Scheme 1) was on stage and we will shed light on it as an emblematic achievement. Taking the example of a reduction of a neutral organic molecule, injection of an electron makes it more basic or nucleophile and the electron transfer event is often followed by an irreversible chemical reaction, for example protonation or expulsion of a nucleophile, leading to a neutral radical usually more reducible than the starting molecule, then triggering a second electron transfer. Such an overall bi-electronic irreversible process may follow several pathways that are worth investigating in particular to predict possible branching processes. One important question is whether the second electron is transferred directly from the electrode (ECE) or from the solution species, namely the singly reduced species via a disproportionation reaction (DISP) as sketched on Scheme 1. Investigation of the ECE/DISP dichotomy by J-M Savéant started in 1968 with a first theoretical analysis ${ }^{7}$ and experimental illustration. ${ }^{8}$ It reached its climax in 1977 and 1979 with the publication of the general resolution of the problem. ${ }^{9,10}$ Notably, this decade journey involved several important students and then collaborators of J-M. Savéant, C. Andrieux, ${ }^{11}$ L. Nadjo, ${ }^{12}$ and the decisive contribution of Christian Amatore. ${ }^{9,10}$

Scheme 1. ECE-DISP mechanisms

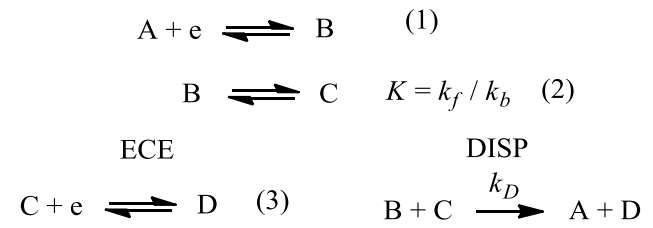

DISP1: (2) rate determining step

DISP2: (2) at equilibrium, (4) rate determining step

This ECE/DISP problem illustrates the methodology put forward by J-M. Savéant to study mechanisms with molecular electrochemistry: (i) set the diffusion-reaction systems, (ii) use a dimensionless formulation to derive the minimal number of governing parameters, (iii) explore limiting cases corresponding to extreme values of the governing parameters, and (iv) draw zone diagrams showing how the system, and hence the CV and its characteristics (shape, intensity, position), is modified upon varying the experimental parameters (scan rate, concentrations, etc.). Finally, (v) illustrative systems are studied and reported.
In the specific case of the ECE/DISP competition, three mechanisms are involved: ECE, DISP 1 and $\mathrm{DISP}_{2}$ (Scheme 1). Considering "pure kinetics" conditions, i.e. when a stationary state is obtained for intermediates due to mutual compensation of diffusion and chemical reaction, the system is governed by two parameters, $K=k_{f} / k_{b}$ the equilibrium constant of the first chemical step and $\left(\frac{R T}{F v} k_{D} C^{0}\right)\left[\frac{F v}{R T\left(k_{f}+k_{b}\right)}\right]^{3 / 2}$ a competition parameter $(F$ is the Faraday, $T$ the temperature, $R$ the gas constant, $v$ the scan rate and $C^{0}$ the bulk concentration of the substrate A). The resulting zone diagram is shown in Figure $1 \mathrm{~A}$, revealing three distinct zones where only one mechanism is dominant, as well as transitions zones where two mechanisms are in competition, and a general zone for which all three mechanisms are operatives. The effect of the various parameters (scan rate $v$, substrate concentration $C^{0}$, equilibrium constant $K$, rate constant $k_{D}$ and $k=k_{f}+k_{b}$ ) are anticipated via the arrows in the upper right compass. Boundaries between zones are determined using criteria on either peak potential $\left(E_{p}\right), E_{p} v s . \log v$ slope, or peak width. Whereas the effect of rate constants and substrate concentration is intuitively easily predicted from the observation that the first chemical step is first order (large $k$ leads to $C$ being produced close to the electrode surface and hence reduced by the electrode), disproportionation is second order (favored for high concentration of substrate) and so the effect of scan rate is difficult to anticipate. The theoretical analysis shows that low scan rate favors the ECE mechanism.

A

B
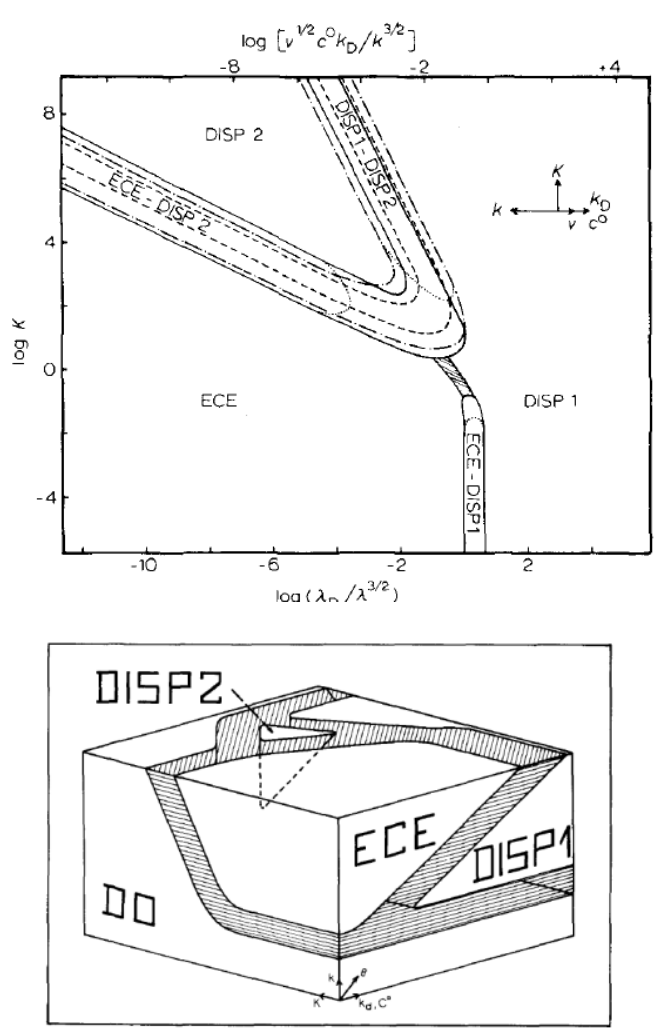
C

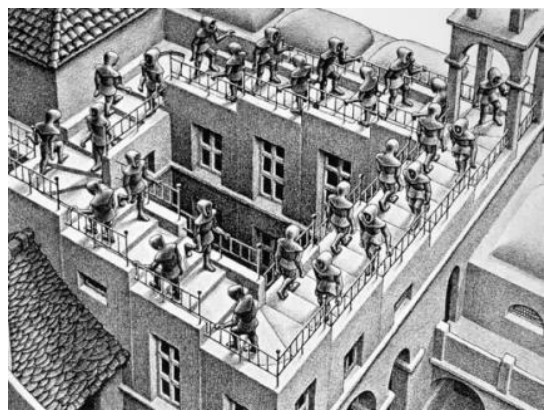

Figure 1. (A) ECE-DISP zone diagram adapted from ref. 9. (B) ECE-DISP 3D zone diagram adapted from ref. 10. (C) Escher drawing viewed as a "zone diagram cartoon".

The general case, i.e. removing the "pure kinetics" conditions, involves three governing parameters, the thermodynamic constant $K$, and both kinetic parameters $\lambda_{D}=k_{D} C^{0} /(R T / F v)$ and $\lambda=k /(R T / F v)$ leading to the three-dimensional zone diagram shown on Figure 1B. These formal analyses were used to study experimental systems based on organic molecules by the group of J-M. Savéant, ${ }^{13}$ but also others, ${ }^{14}$ and it was shown to apply to transition metal complexes underscoring the generality of the concepts. ${ }^{15}$ Note that the use of zone diagrams is very convenient in mechanism analysis although it is often viewed by neophytes as confusing labyrinth as cartooned on Figure 1C.

As already mentioned, the development of cyclic voltammetry in organic solvents was an opportunity to investigate in details outersphere interfacial electron transfers and test predictions of the Marcus-Hush theory developed in the late 60 's. ${ }^{16}$ One of the peculiar features of ET theories is the prediction that the transfer coefficient depends on the potential. In other words, the nonlinear character of the kinetic law should be revealed if current-potential curves can be analyzed over large range of potentials. This was made possible via the use of the convolution technique. ${ }^{17,18,19,20}$ The basis of the method is simply a mathematical manipulation of the raw data obtained from $\mathrm{CV}$ using the function $1 / \sqrt{\pi t}$ characteristic of transient linear semi-infinite diffusion. ${ }^{21}$ This allows calculating the convolution integral from the experimental data. It is of particular interest to extract the kinetic law for a simple electron transfer process without any assumption on the form of the rate law following the procedure described in ref. 22 . One important achievement of the use of convolution on $\mathrm{CV}$ data was the demonstration that the transfer coefficient varies linearly with potential in the case of reduction of tert-nitrobutane, ${ }^{23}$ as predicted by the Marcus-Hush theory (Figure 2). ${ }^{16}$

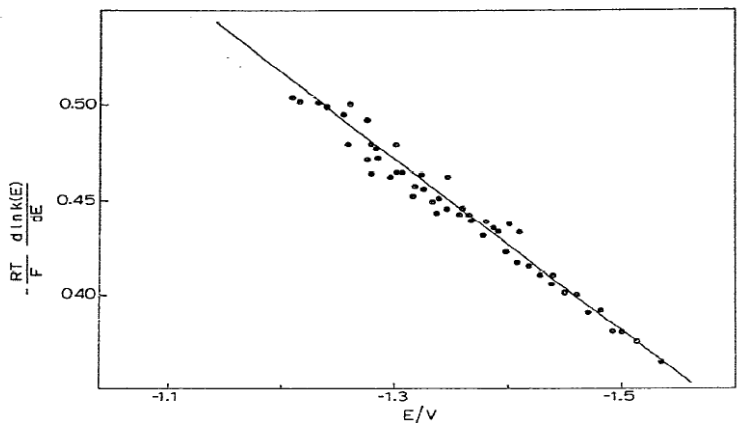

Figure 2. Tert-nitrobutane in DMF. $-(R T / F) \frac{d \ln k(E)}{d E}$ as a function of the electrode potential $E$ referred to $\mathrm{Ag} / \mathrm{AgI}$ reference electrode $(k(E)$ is the electron transfer rate constant). Adapted from ref. 23.

Convolution potential sweep voltammetry was used up to scan rate in the range of $\mathrm{kV} / \mathrm{s}$ to study electrochemical kinetics. ${ }^{24}$ Technical limitations had to be overcome to reach such high scan rates at that time. While the emergence of CV as a popular technique in the 60's was partly due to the availability of amplifiers allowing the development of potentiostats, limitations resulting from the bandpass of the amplifiers and from the influence of ohmic drop effect on the faradaic current were still a problem at high scan rates. J-M. Savéant's contribution in this area of instrumentation is noticeable through the early development of a potentiostat enabling ohmic drop compensation via positive feedback. ${ }^{25}$ Later he was also involved in the development of instrumentation dedicated to fast voltammetry at ultramicroelectrodes ${ }^{26}$ as well as in the use of a more specific technique: laser pulse photoinjection of electrons from metal electrodes and its application to study organic radicals in aprotic solvents. ${ }^{27}$ Although J-M. Savéant's contribution in the formal description of mechanism analysis is particularly noticeable, his interest for instrumentation was constant as he was convinced that solid experimental data are a pre-request for mechanism understanding. Hence, he was always warning students of possible misinterpretation if using a technique without being aware of instrumentation artifacts as was the case for the use of second-harmonic ac voltammetry. ${ }^{28}$

Besides investigation of electrochemical reactions, analytical electrochemical techniques, such as cyclic voltammetry, can be used to trigger non-electrochemical reactions. In such a case, the electrode or more precisely electrons are catalysts. This field of electron catalyzed chemical reactions is currently experiencing a renewed large interest, ${ }^{29}$ but it was already investigated in the $80^{\prime} \mathrm{s}^{30} \mathrm{~A}$ prominent example was the detailed study of "aromatic $S_{\mathrm{RN}} 1$ " substitution reactions. ${ }^{31}$ Not only did J-M. Savéant show that these reactions can be triggered by an electrode but, following his typical approach, he did formalized the problem and used typical examples to decipher the mechanism. Substitution of a halide ion or other leaving groups by a nucleophile at an aromatic carbon does not occur spontaneously. It requires induction by an electron or by light. A typical example is the reaction of 4-bromobenzophenone 
with thiophenolate triggered at an electrode polarized at a potential allowing reduction of the substrate ArX. Only 0.2 electrons per substrate is consumed while the conversion yield is $80 \%$. This can be rationalized by the mechanism depicted in Scheme 2. Cyclic voltammetry appeared as a useful tool to study such processes. The critical bottleneck of the mechanism is the fate of the radical $\mathrm{Ar}^{\bullet}$ which can either be reduced (ECE/DISP mechanism), leading to a two-electron $\mathrm{CV}$ wave, or react with the nucleophile to produce the anion radical which can then oxidize at the electrode or diffuse in solution to enter a loop consuming the substrate, and thereby to a zero electron wave. ${ }^{32}$

Scheme 2. Electrochemically induced SRN1 mechanism

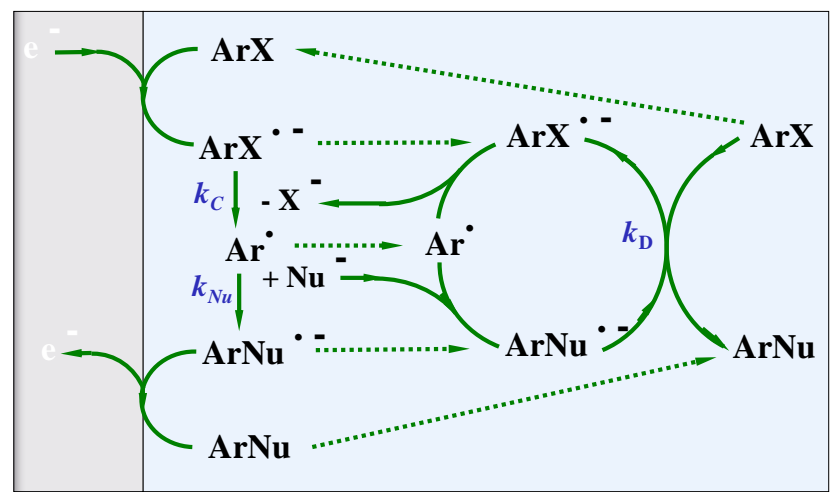

A typical example is shown in Figure 3, where the reduction of chloroquinoline is observed in the absence (dashed line) and in the presence of a nucleophile acetone enolate (full line). Wave D features the two-electron formation of $\mathrm{ArH}$ in the absence of nucleophile. When nucleophile is added, the decrease of the waves magnitude indicates that the substitution reaction occurs.

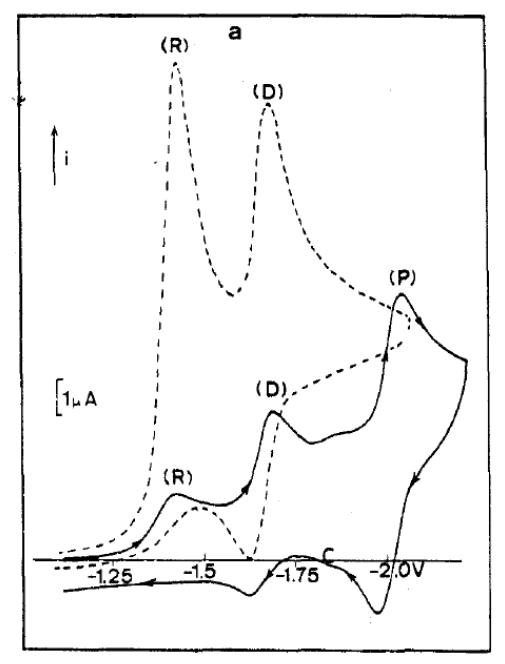

Figure 3. Cyclic voltammetry of 2-chloroquinoline (1.75 mM) in liquid $\mathrm{NH}_{3}$ at $-40^{\circ} \mathrm{C}$. Scan rate $0.2 \mathrm{~V} / \mathrm{s}$. (dashed line) Without nucleophile added and (full line) in the presence of the nucleophile $\left(0.025 \mathrm{M} \mathrm{CH}_{2} \mathrm{COCH}_{2}{ }^{-}\right)$. Adapted from ref. 30 .

Hence, analysis of current decrease as function of nucleophile addition allows for a quantitative analysis of the kinetics of nucleophile addition on the intermediate radical. More specifically, as in the case of the ECE/DISP dichotomy, J-M. Savéant has provided a rigorous description, showing that the ECE/DISP/substitution competition is governed by two kinetic parameters involving both rate constants and operational parameters: $\quad \sigma=k_{C} / k_{N u}\left[\mathrm{Nu}^{-}\right] \quad$ and $\rho=\left(k_{D} C^{0} / k_{N u}\left[\mathrm{Nu}^{-}\right]\right)\left((F v / R T) / k_{C}\right)^{1 / 2} \quad\left(k_{C}\right.$ is the rate constant of $\operatorname{ArX}^{\bullet-}$ cleavage, $k_{N u}$ is the rate constant of nucleophile addition on $\mathrm{Ar}^{\bullet},\left[\mathrm{Nu}^{-}\right]$is the bulk concentration of nucleophile, $C^{0}$ is the bulk concentration of the substrate ArX, $k_{D}$ is the rate constant of homogeneous electron transfer, see Scheme 2). A 2D zone diagram was drawn (Figure 4) showing the domain of prevalence of each mechanism. This provides a unique tool to understand the paradox of such system in the sense that the electrochemical inducement (reduction of $\mathrm{ArX}$ producing $\mathrm{ArX}^{\bullet-}$ and $\mathrm{Ar}^{\bullet}$ allowing the substitution to occur) involves the simultaneous destruction of the key species $\mathrm{Ar}^{\bullet}$ via its reduction (at the electrode or by $\mathrm{ArX}^{\circ-}$ ), which then stops the radical chain substitution process. In the ECE situation, reduction of $\mathrm{Ar}^{\bullet}$ at the electrode is prevented by its trapping by $\mathrm{Nu}^{-}$. Hence, $\sigma$ has to be small for substitution to be dominant (bottom left of the zone diagram). In the DISP situation, $k_{N u}\left[\mathrm{Nu}^{-}\right]$is opposed to $k_{D}$ and has to be large again to favor substitution over homogeneous reduction. A large value of $k_{C}$ is also favorable as it lowers the efficiency of the homogeneous reaction. However, $k_{C}$ should not be too large otherwise the ECE mechanism is again dominant (e.g. progressive transition from SUBST to ECE-SUBST and then ECE zone as shown on the bottom part of Scheme 1).

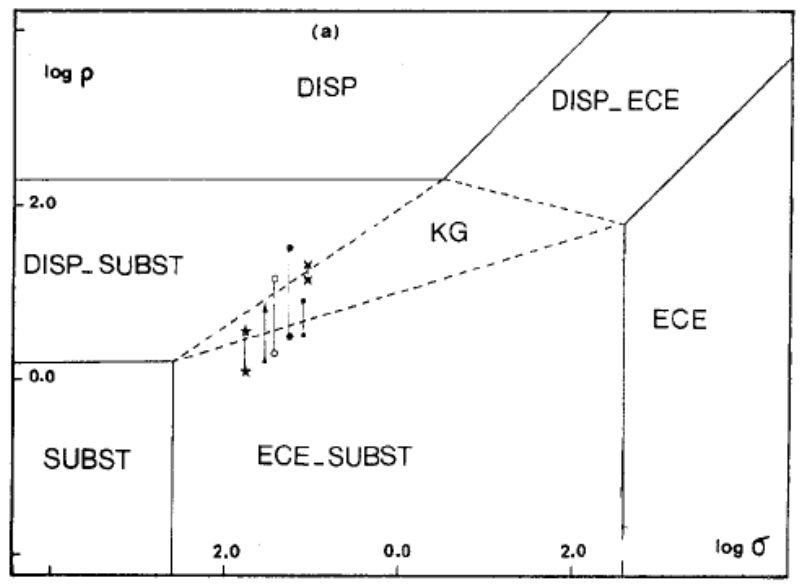

Figure 4. ECE-DISP-SUBST zone diagram. Adapted from ref. 30.

Deciphering the $\mathrm{S}_{\mathrm{RN}} 1$ mechanism induced electrochemically was not only an achievement per se but it exemplifies how the tools of molecular electrochemistry can be used to study non-electrochemical reactions and get a deep understanding on how kinetic competition, including mass transport, can drive the efficiency or selectivity of chemical reactions. 
The use of an electrode to perform an electrosynthesis at large scale requires the process to be studied under "real conditions", i.e. corresponding to macroelectrolyses at large current densities with vigorous stirring of the solution or under flow conditions (circulation of the solution). The question on whether the information retrieved from analyses performed using analytical non-destructive methods such as $\mathrm{CV}$ can be transposed to predict product distribution in bulk electrolysis, for example, was of interest for J-M. Savéant as he always kept in mind that practical application is one of the final goals of studying reactions. Hence, together with $\mathrm{C}$. Amatore they have provided a thorough description of product distribution in preparative electrolysis. $33,34,35,36,37,38,39,40$ They have shown that the establishment of the relationship between mechanism and governing parameters, on the one hand, and product distribution, on the other hand, requires similar approaches as those developed for CV. An interesting outcome is that the operational conditions, for example current density, can in some cases change the product distribution. This has been exemplified in the case of direct $\mathrm{CO}_{2}$ reduction in DMF at a mercury electrode (oxalate vs. CO as products). ${ }^{41}$ This analysis could be profitable in the present context of revival of the synthetic organic electrochemistry. 42

\section{Catalysis in Molecular and Biomolecular Electro- chemistry}

Molecular catalysis of electrochemical reactions is nowadays a very popular process. It is amazing to realize that molecular catalytic processes were of primarily interest of pioneers of molecular electrochemistry, with the first experimental illustration being reported almost six years after the formal derivation of the CV equations. ${ }^{43,44}$ The studied system was an inorganic system. Because in the following years the focus of molecular electrochemistry was on organic electrochemistry, catalytic processes were not explored until the concept of redox catalysis emerged. Redox catalysis corresponds to the reaction scheme shown on Scheme 3 (for the case of a reduction): the direct reduction of a substrate $\mathrm{A}$ is replaced by its reduction by the electrogenerated outersphere electron donor $Q^{.45,46,47,48,49,50}$ As both the direct and indirect reduction of the substrate are outersphere, one may wonder why catalysis occurs. Why can the homogeneous reductant provide reduction of the substrate at more anodic potentials than the electrode? The answer is that the electrons are confined in a twodimensional space at the electrode surface, whereas they are dispersed in a three-dimensional space once transferred on the redox catalyst. ${ }^{51}$ Therefore, redox catalysis can be named "physical catalysis", the diffusion-reaction layer where reduction of the substrate occurs being viewed as a "volumic electrode" and the catalyst rather viewed as an electron mediator (Note that redox catalysis was developed around the same time by Henning Lund and coworkers ${ }^{52}$ ).
Scheme 3. Redox catalysis vs. chemical catalysis

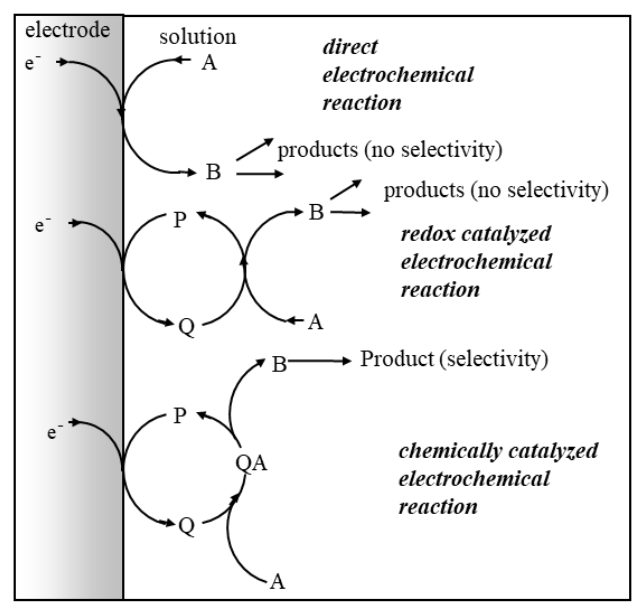

Redox catalysis proved to be a very useful tool to investigate short-lived intermediates such as anion radicals or cation radicals. ${ }^{53,54,55}$ Indeed, high scan rate CVs is source of kinetic information on the fate of electrogenerated species, but it is limited to the sub-microsecond domain (if ultramicroelectrodes are used) and so to the determination of first order rate constants as high as $10^{7} \mathrm{~s}^{-1}$ at scan rate of $10^{6} \mathrm{~V} \cdot \mathrm{s}^{-1}$. This is based on the rough estimation that the competing parameter $\lambda=k_{C} /(F v / R T)$ ( $k_{C}$ being the rate constant of intermediate cleavage) should be less than 0.25 to get some reversibility. In the framework of redox catalysis, the short-lived species is obtained from an homogeneous electron transfer between the electrogenerated active form of the catalyst and the substrate. This uphill electron transfer is driven by the fast evolution of the short-lived intermediate. Provided the homogeneous electron transfer is at equilibrium, the catalytic response is governed by $\gamma=C^{0} / C_{c a t}^{0}\left(C^{0}\right.$ is the bulk concentration of the substrate A and $C_{c a t}^{0}$ the bulk concentration of the catalyst $\mathrm{P}$ ) and $\lambda_{c a t}=k_{C} \exp \left(\frac{F}{R T}\left(E_{\mathrm{A} / \mathrm{B}}^{0}-E_{\mathrm{P} / \mathrm{Q}}^{0}\right)\right) /(F v / R T)$ where $E_{\mathrm{A} / \mathrm{B}}^{0}$ and $E_{\mathrm{P} / \mathrm{Q}}^{0}$ are the standard potential of the substrate and catalyst, respectively. As soon as $\lambda_{\text {cat }} \gamma$ is large enough (typically larger than 0.1 ), catalysis is observed in $\mathrm{CV}$ (i.e. $i_{p} / i_{p}^{0}>1$, where $i_{p}$ is the CV plateau or peak current in the presence of substrate $\mathrm{A}$, and $i_{p}^{0}$ the $\mathrm{CV}$ peak current of the catalyst alone) and $k_{C}$ can be determined if both standard potentials are known. The upper limit for accessible $k_{C}$ is dictated by the condition of the homogeneous electron transfer to remain at equilibrium, which implies typically that $k_{-e} C_{c a t}^{0} / k_{C}>0.25$ (where $k_{-e}=k_{d i f}$ is the backward homogeneous electron transfer rate constant, i.e. the rate constant for reaction between $\mathrm{P}$ and $\mathrm{B}$, usually 
assumed to be controlled by diffusion). In other words, whereas in the direct method the cleavage step rate constant is compared to the diffusion rate $F v / R T$ (controlled by the scan rate), in the indirect redox catalysis method $k_{C}$ is compared to the downhill diffusion controlled backward homogeneous electron transfer, setting the upper limit to $k_{C}<4 k_{d i f} C_{c a t}^{0} \approx 10^{9} \mathrm{~s}^{-1}$ taking $C_{c a t}^{0} \approx 0.05 \mathrm{M}$ as maximal accessible value. ${ }^{56}$ Hence, the indirect method based on redox catalysis allows to determine intermediates lifetimes in the nanosecond regime. We note that getting faster and faster cleavage of bonds leads to the idea that the intermediate lifetime might be smaller than a vibration, hence leading to a concerted dissociative electron transfer. This idea (already proposed by N. S. Hush in 1952 and $1957{ }^{57}$ ) opened a new chapter of the fast field of electron transfer. We will review the important contribution of J-M. Savéant in this field in the last section. In the case where the intermediate does exist, cleavage of aromatic halides (ArX) was studied and rate constants have been gathered by several research groups from both direct and indirect electrochemical measurements, as well as from pulse radiolysis over many orders of magnitude. Interestingly the logarithm of these rate constants shows a rough linear correlation with the standard rate constant for the formation of the anion radical (Figure 5). These data were rationalized within the framework of the model of intramolecular dissociative electron transfer (see last section) including an out-of-plane bending of the cleaving bond allowing avoidance of a conical intersection. ${ }^{58}$ It is a salient example where the use of a methodology developed for molecular electrochemistry allows to decipher and to illustrate important and general Physical Chemistry phenomena.
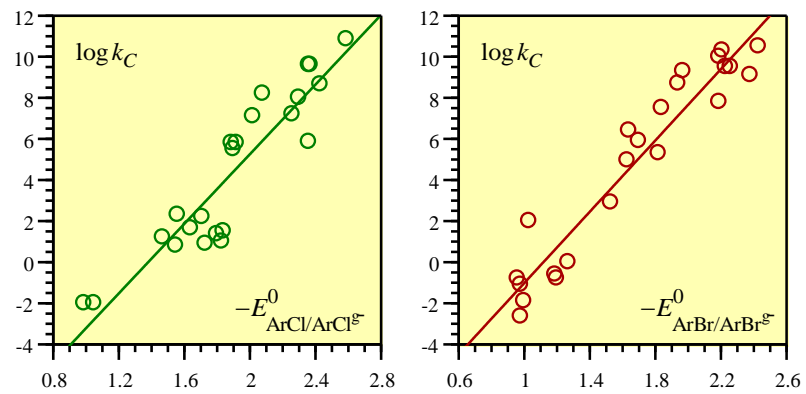

Figure 5. (left) Correlation between the cleavage rate constants and the standard potential for aryl chlorides. From left to right: Ar: 2-nitrophenyl, 4-nitrophenyl, 9,10chloroanthracenyl, 4,4'-chlorobenzophenone, 2benzaldehyde, 4-benzoylphenyl, 9-anthacenyl, 1-anthacenyl, 2-anthacenyl, 3-acetylylphenyl, 4-(2-(4-pyridyl)vinyl)phenyl, 4-quinolyl, 4-acetylphenyl, 2-quinolyl, ethyl 4benzoate, 4-cyanophenyl, 1-naphthyl, 2-naphthyl, 3-pyridine, 2-biphenyl, 2-pyridine, 3-biphenyl, 4-biphenyl. (right) Correlation between the cleavage rate constants and the standard potential for aryl bromides. From left to right: $\mathrm{Ar}^{\circ}$ : 2isopropyl-4-nitrophenyl, 4-nitrophenyl, 2-methyl-3nitrophenyl, 2-methyl-4-nitrophenyl, 2-nitrophenyl, 3fluorenyl, 1-fluorenyl, 2,6-dimethyl-4-nitrophenyl, 3benzoylphenyl, 4-benzoylphenyl, 5-methoxy-psoralenyl, 9- anthacenyl, 3-acetylylphenyl, 4-acetylylphenyl, 4benzonitrile, ethyl-4-benzoate, 1-naphthyl, 1-naphtyl, 2naphtyl, 3-pyridine, 2-pyridine, 3-biphenyl, 4-biphenyl. Adapted from ref. 58.

Reduction of organic halides does not necessarily occur via an outersphere electron transfer. If there is a more intimate contact between the electrogenerated reductant and substrate, then we enter the realm of chemical catalysis (Scheme 3). Chemical catalysis is superior to redox catalysis as it allows for not only avoid high energy intermediates, but also for controlling reaction selectivity. It has been illustrated by J-M. Savéant ${ }^{51}$ via, for example, a thorough study of the reduction of vicinal dibromides with electrogenerated aromatic anion radicals (redox catalysis) or transition metals porphyrins (chemical catalysis). ${ }^{59}$ The plot of the catalytic rate constants measured by cyclic voltammetry as a function of the driving force of the homogeneous reduction reaction shows (Figure 6) that the $\mathrm{Zn}$ and $\mathrm{Cu}$ porphyrins behave as outer-sphere electron donors, as does the free base, whereas the $\mathrm{Co}, \mathrm{Fe}$ and $\mathrm{Ni}$ data points stand well above the outer-sphere line. This example is the occasion to highlight the important role of the late Doris Lexa, a longtime collaborator of J-M. Savéant in the domain of bioinspired molecular electrochemistry and in particular on the electrochemistry of vitamin B1260 and iron porphyrins and their catalytic activity.
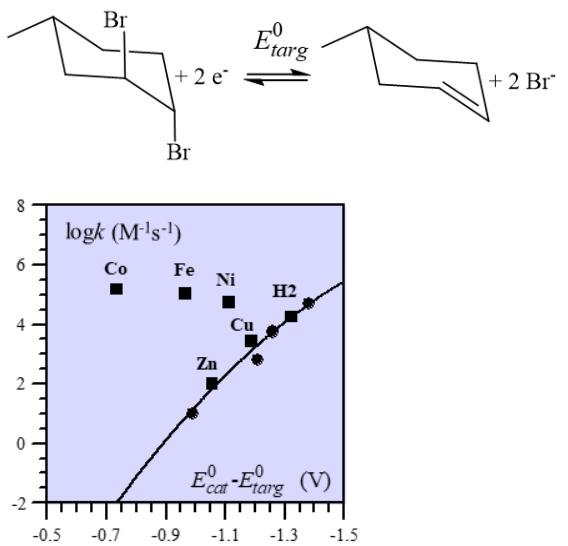

Figure 6. Catalysis of the electrochemical reduction of 1,2dibromocyclohexane into the corresponding olefin (Scheme 3 ) in $\mathrm{DMF}+0.1 \mathrm{M} \mathrm{Bu}_{4} \mathrm{NBF}_{4}$ by anion radicals of aromatic hydrocarbons (solid circles) and by the redox couples obtained by one-electron reversible reduction of ETIOP porphyrins (see Figure 2 for the definition of the ETIOP ring) of $\mathrm{Co}^{\mathrm{II}}, \mathrm{Fe}^{\mathrm{II}}, \mathrm{Ni}^{\mathrm{II}}, \mathrm{Zn}^{\mathrm{II}}, \mathrm{Cu}^{\mathrm{II}}$ and the free base (H2) (solid squares), from the data in ref. 59. The full line represents the fitting of these data points by the quadratic law for the dissociative electron transfer by outer-sphere one-electron donors according to the Morse curve model.111

As shown above, the concept of homogeneous catalysis of electrochemical reactions has gained popularity for redox organic transformations in the late 80 's, ${ }^{61}$ but J-M. Savéant also saw its potentiality for the activation of small molecules, in particular $\mathrm{CO}_{2}$ reduction. ${ }^{62,63}$ It is worth mentioning that he was involved in the field of $\mathrm{CO}_{2}$ 
electroreduction for a long time with several important contributions to the direct reduction of $\mathrm{CO}_{2},{ }^{64,41}$ in particular the determination of the standard potential of the $\mathrm{CO}_{2} / \mathrm{CO}_{2}{ }^{\bullet-}$ couple in aprotic dimethylformamide $(-2.2 \mathrm{~V} v \mathrm{v}$. SCE). ${ }^{65}$ Molecular catalysis of electrochemical reactions is now experiencing its golden age via the thriving development of small molecules activation with transition metal complexes as molecular catalysts. In front of this contented situation, it was necessary to get a rational benchmarking of catalysts for a given reaction. Although the concept of diffusion-reaction layer for catalysis in pure kinetics conditions was known for a long time, it was the occasion to highlight its importance for an adequate evaluation of the turnover frequency (TOF) of a catalyst and its relationship with the applied potential in the case of the simple mechanism depicted in Figure 7.66 This led to the introduction of the catalytic Tafel plots relating TOF to overpotential (defined as the difference between the electrode potential and the standard potential of the targeted reaction).
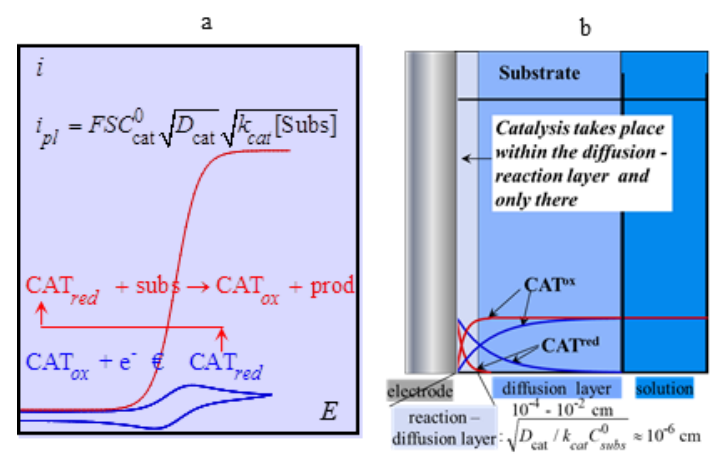

c

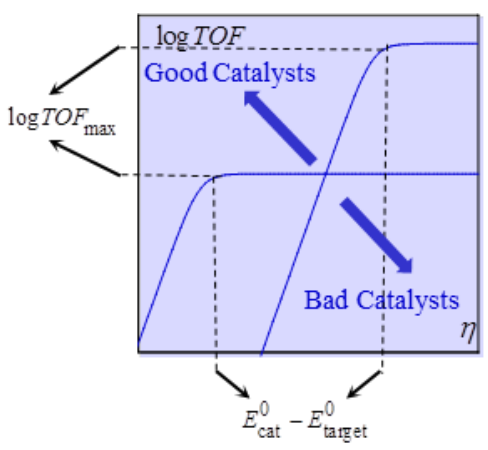

Figure 7. One-electron/one step catalytic reaction scheme under canonical conditions. (a) Reaction scheme and its current-potential response in the absence (blue) and presence (red) of the substrate, as well as equations of the plateau current. (b) Concentration profiles in the absence of substrate (blue) and in canonical conditions (red). The representation takes the case of a reductive process as example. Transposition to oxidations is straightforward with the help of appropriate changes of sign. $i$ : current, $E$ : electrode potential. $E_{\text {cat }}^{0}$ : standard potential of the $\mathrm{CAT}_{o x} / \mathrm{CAT}_{\text {red }}$ redox couple. $i_{p l}$ : plateau current. $S$ : electrode surface area. $C_{\text {cat }}^{0}:$ bulk concentration of the catalyst. $D_{\text {cat }}$ : average of the diffusion coefficients of all forms of catalyst. $k_{\text {cat }}$ : second order rate constant of the catalytic step. [Subs]: concentration of sub- strate. (c) Catalytic Tafel plot.

Extraction of the catalytic rate constant is easily performed from the plateau current obtained in canonical conditions for mechanisms where the rate determining step is the first irreversible chemical step following the catalyst activation. Note that if the plateau current is not reached, increasing the scan rate or analysis of the foot-of-the wave may be an alternative strategy. ${ }^{66}$ This methodology was used intensively to explore $\mathrm{CO}_{2}$ reduction with catalysts from the family of iron porphyrins. J-M. Savéant's group first emphasized the crucial role of acids in bolstering the catalytic rate. ${ }^{67}$ Then, taking advantage of the knowledge gathered on proton-coupled electron transfer and its coupling with bond breaking processes, the mechanism was studied in details leading to a rational design of a more efficient catalyst. ${ }^{68}$ Similarly, analysis of substituents effects revealed an "iron" law correlating the standard potential of the catalyst and the catalytic rate constant, again illustrating that molecular electrochemistry is a convenient tool to decipher physical chemistry laws of reactivity. ${ }^{69}$ It was however shown that the "iron law" can be broken by introducing through space electrostatic effects leading to a highly efficient molecular catalyst for the conversion of $\mathrm{CO}_{2}$ to $\mathrm{CO}$ (Figure 8 ). ${ }^{70}$
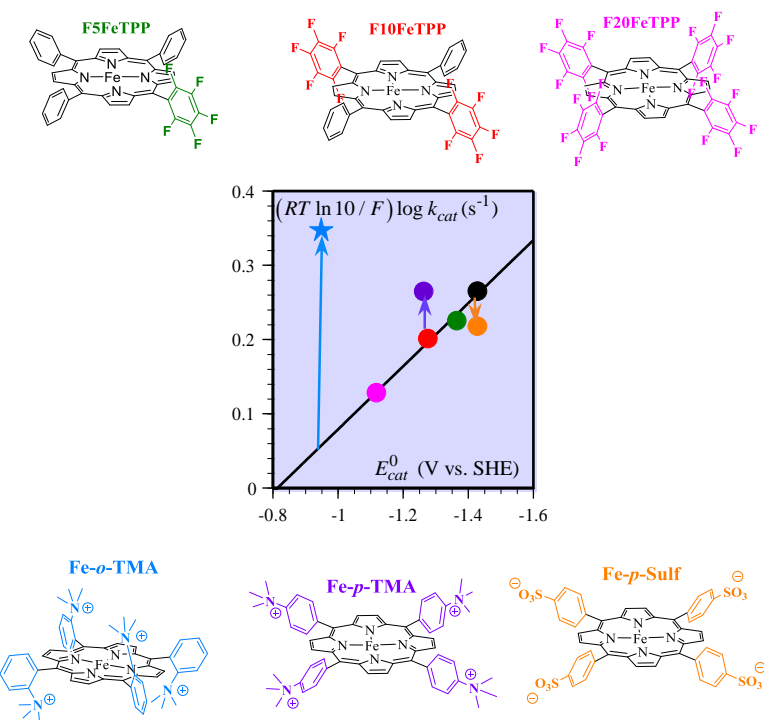

Figure 8. Molecular catalysis of $\mathrm{CO}_{2}$ to $\mathrm{CO}$ reduction with iron porphyrins. Catalytic rate constant as function of the standard potential of the $\mathrm{Fe}(0) / \mathrm{Fe}(\mathrm{I})$ couple. Adapted from ref. 70.

An important lesson that collaborators of J-M. Savéant learned by working at his side is that basic laws of Physical Chemistry cannot be escaped and that pitfalls in reasoning or data analysis should be tracked to avoid misadventures. We already mentioned instrumentation artifacts that he revealed..$^{28}$ In the field of catalysis of electrochemical reactions, many traps can be met and he considered as an important task to make sure that false ideas or reasoning do not propagate. ${ }^{71}$ One of the last misanalysis he fought against was the idea that the maximal turnover frequency of a homogeneous catalysis of an electrochemical reaction could be correlated to the equilibrium free energy of the reaction. ${ }^{72}$ Such an intermingling of rate constants, standard quantities and concentration is misleading as was the 
flawed concept of $\mathrm{pH}$ dependent driving force for protoncoupled electron transfer. ${ }^{73}$

Because J-M. Savéant was very cautious on experimental results, as already mentioned, he got involved in the design of potentiostats able to adequately correct CVs for ohmic drop. Correction for ohmic drop is also important for catalytic CVs (except for the plateau current) if one aims at retrieving kinetic information from the shape of the wave, in particular the effect of electron transfer between the electrode and the catalyst. ${ }^{44,74}$ In that regard another pitfall is that the surface state of the electrode might be source of errors. In molecular electrochemistry, it is generally preferred that the electrode behaves as an outersphere electron donor or acceptor. Even considering this state of affair, artifacts are still possible as partial coverage of the electrode surface by an isolating film can lead to an apparent slowness of the electron transfer. This has been demonstrated by J-M. Savéant and C. Amatore in a seminal paper, ${ }^{75}$ showing the effect of constrained diffusion around actives sites. This constrained diffusion may actually also occur at the entrance of a thick coating with channels and containing immobilized molecular catalysts. Then, the next step is the question of transport of both substrate and electron through this catalytic film and their entanglement with the catalytic reaction. The contribution of J-M. Savéant in this field is also very important and started in 1978 when the interest of redox polymers and modified electrode for catalysis was growing. ${ }^{76}$ An analysis of electron transport by hopping in such films was provided leading to a modified Nernst-Planck equation, ${ }^{77}$ the description being later refined by consideration of percolation effects. ${ }^{78}$ Ohmic conduction in mesoporous electrodes was also more recently studied considering a transmission line model as initially introduced by R. De Levie, ${ }^{79}$ the effect of ohmic drop being carefully analyzed. ${ }^{80}$ Note that this question is intimately related to the field of electrochemical energy storage, a domain of recent interest for J-M. Savéant to which he contributed via the revisit of the notion of "pseudocapacitance" initially proposed by B. Conway. ${ }^{81}$

Kinetics of electrochemical reactions mediated by derivatized electrodes or redox polymers films with electron hopping as electron transport was thoroughly investigated in the framework of steady-state methods (rotating disk electrode) $82,83,84,85,86,87,88$ and more recently in the framework of cyclic voltammetry. ${ }^{89,90,91}$ Considering fast catalysis, the interplay of electron transport, substrate transport and catalytic reaction is conveniently represented via the kinetic zone diagram shown in Figure 9 for a simple one step mechanism. Application of the formal description to several experimental systems was achieved through a fruitful collaboration between J-M. Savéant and the group of F. Anson at Caltech. ${ }^{92,93}$ This collaboration led to further developments in which the role of charge transport relay and catalysts are separated via the incorporation of a redox shuttling species within the film. This was illustrated with the catalytic oxygen reduction by a cobalt porphyrin as catalyst (Scheme 4). ${ }^{94}$ Another refinement of the modelling was done in collaboration with the group of A. J. Bard at the University of Texas with the introduction of a finite mass transfer rate of the substrate across the film-solution interface. ${ }^{95}$ Studies of molecular catalysts immobilized in a film coated on the surface of an electrode are currently experiencing a lot of interest in the context of contemporary energy challenges and in particular for $\mathrm{CO}_{2}$ reduction. ${ }^{96}$

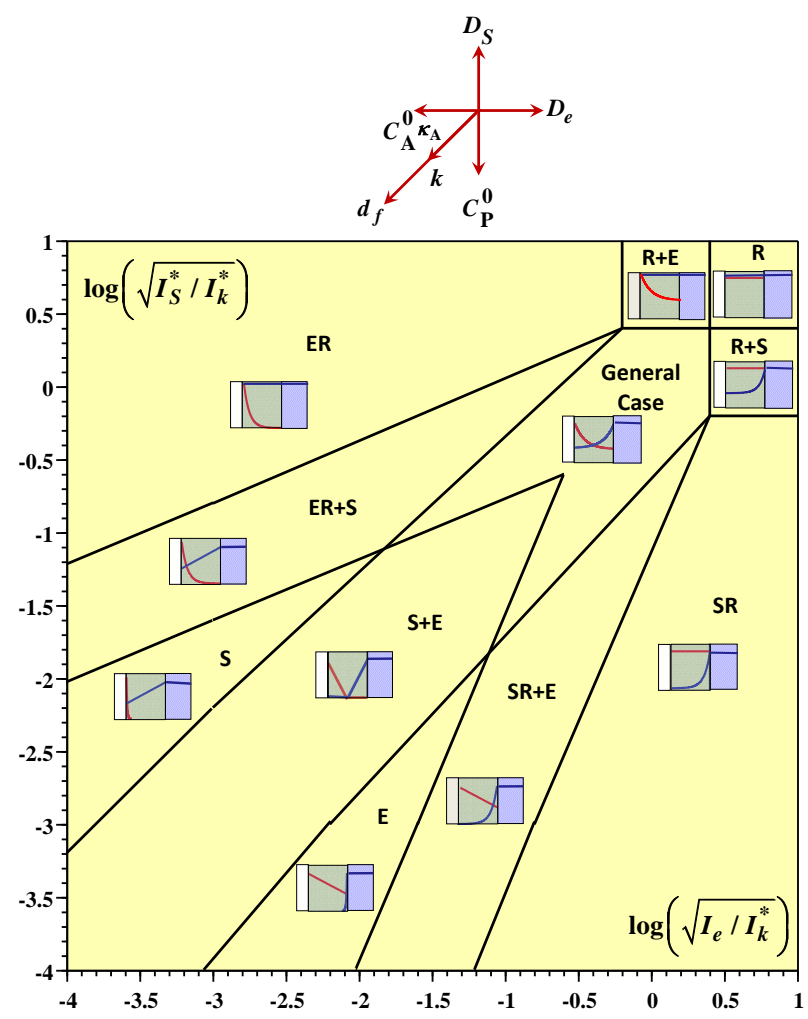

Figure 9. Kinetic zone diagram. The arrows above the diagram allows traveling through the zone diagram upon varying the experimental parameters, in direction and magnitude (log). The inserts show the concentration profiles of the reduced catalyst (red) and substrate (blue). Adapted from ref. 91.

Scheme 4. Catalysis of the reaction of $\mathrm{O}_{2}$ by $\mathrm{Ru}\left(\mathrm{NH}_{3}\right)_{6}{ }^{2+}-$ Co(II)tetrakis(4- $N$-methylpyridyl)porphyrin-Nafion film. Adapted from ref. 94.

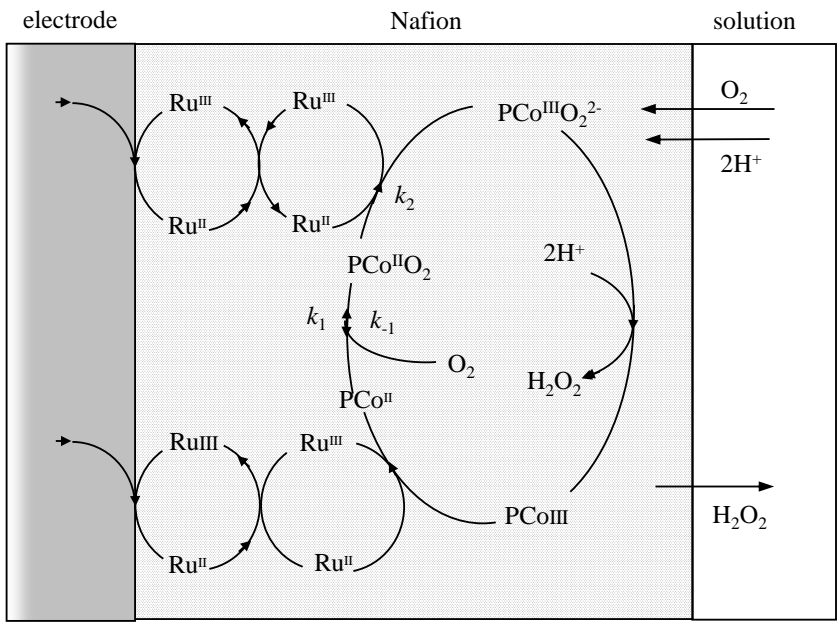

From the early days of molecular electrochemistry, J-M. Savéant was well aware that the concepts developed, in 
particular for catalysis, were useful not only in the field of organic electrochemistry, which was developing fast at that time, but also in the field of coordination chemistry as shown by its intensive work on vitamin B12. ${ }^{60}$ Beyond molecular electrochemistry the concepts are also useful to develop the field of biomolecular electrochemistry. It is the reason that he got increasingly involved in problems of biological interest. This was particularly true when Jacques Moiroux $^{97}$ joined the Laboratoire d'Electrochimie Moléculaire in 1989 together with his close collaborator Agnès Anne. Their work was first to focus on the study of NADH analog electrochemistry. ${ }^{98}$ Starting in 1993, they got involved in a systematic electrochemical approach to enzymatic catalysis using redox mediators to shuttle electrons between the electrode and the prosthetic group of an enzyme. Catalytic processes where modeled using "PingPong" mechanisms for both enzymes in solution ${ }^{99,100,101,102,}$ or immobilized at the electrode surface in the form of monolayers ${ }^{103,104,105}$ or organized multilayers. ${ }^{106}$ '107 A typical application is the well-studied glucose oxidase which mechanism has been deciphered in details using oneelectron redox mediators ${ }^{100}$ thanks to the important work of Christophe Demaille who is now leading the group "Biomacromolecular Systems - Electron Transport at the Nanoscale" at the Laboratoire d'Electrochimie Moléculaire. Interestingly, it was shown that a precursor complex is formed between the mediator and a site close to the Flavin prosthetic group. This precursor complex allows for molecular differentiation of the enzyme between non-natural redox mediators. ${ }^{100}$ Another piece of work was the thorough analysis of the Horseradish Peroxidase (HRP) mechanism (Scheme 5).

Scheme 5. Mechanism of the Horseradish Peroxidase (HRP)
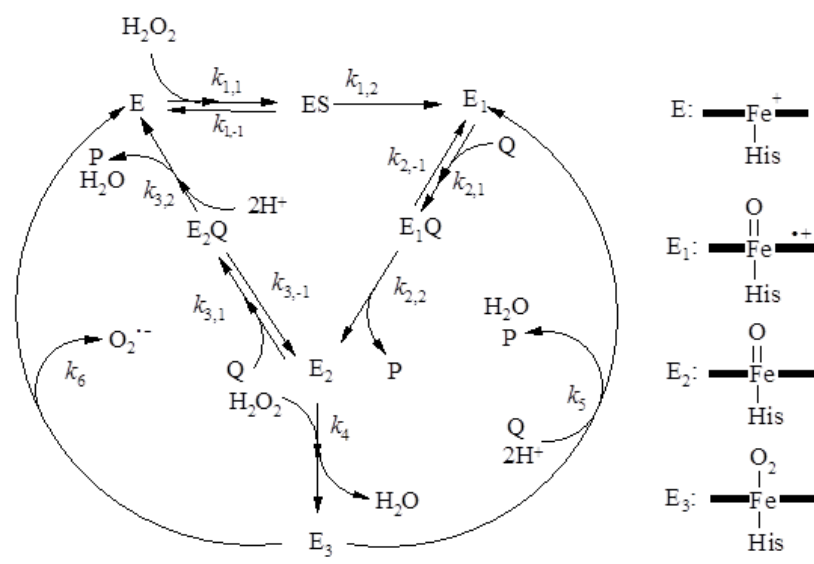

$\mathrm{E}_{2}:-\underset{\mathrm{H} i \mathrm{I}}{\stackrel{\mathrm{O}}{\mathrm{II}}}$

$\mathrm{E}_{3}: \frac{\mathrm{O}_{2}}{\mathrm{I}_{\mathrm{H}}^{\mathrm{F}}}$

P, Q: oxidized and reduced forms of the cosubstrate

HRP has attracted a lot of attention as it is involved in a number of biotechnological applications, but its catalytic process is complex as revealed by the crossings of the catalytic currents observed in cyclic voltammetry in the presence of a redox mediator and increasing concentrations of the substrate $\mathrm{H}_{2} \mathrm{O}_{2}$. The behavior was fully explained via the mechanism depicted in Scheme 5, which involves the intricate coupling between the inactivation of the enzyme by the substrate itself (through the formation of compound $E_{3}$ ) and its reactivation by both the spontaneous release of superoxide (step $k_{6}$ ) and the reduction of the inactivated enzyme by the reduced form of the mediator $\left(k_{5}\right){ }^{101}$ A new function "lms", named after LimogesMoiroux-Savéant, had to be introduced to describe the CVs involving superposition of catalysis with activation and inhibition. Using all experimental observations, a thorough characterization of the mechanism was possible leading to a simulation of the CVs in all conditions including unusual hysteresis and trace crossing features. ${ }^{101}$

As seen above, the work of J-M. Savéant in the field of catalysis encompassed many aspects and always associated formal and conceptual development to experimental illustrations.

\section{Dissociative Electron Transfer - Proton Coupled Elec- tron Transfer}

As already indicated, the study of bond cleavage in transient ion radicals or radicals formed by electron transfer led to the idea that the intermediate lifetime might be smaller than a vibration, hence corresponding to a concerted dissociative electron transfer. Evidences were first gathered from low-temperature $\gamma$ irradiation coupled by ESR characterization for aliphatic halides reductive cleavage. ${ }^{108}$ In 1985 and 1986, J-M Savéant and coworkers reported that the kinetics of homogeneous and heterogeneous reduction of aliphatic halides is consistent with a concerted dissociative electron transfer driven by the standard potential of $\mathrm{RX} / \mathrm{R}^{\bullet}+\mathrm{X}^{-}$couple. ${ }^{109,110}$ Importantly, a non-linear activation-driving force relationship was revealed which could be approximated by a quadratic Marcus-Hush type equation. However, the outersphere electron transfer model developed by Hush and Marcus does not apply to concerted processes as the harmonic vibration approximation for the internal reorganization energy is not compatible with the cleavage of a bond. This prompted for the development of an adequate model proposed in $1987 .{ }^{111}$ A two states model was considered with a Morse curve approximation of the energy of the cleaving bond in the reactant and on the assumption that the repulsive interaction of the fragments product is the same as the repulsive part of the reactant Morse curve (Figure 10). This leads to a quadratic activation-driving force relationship with a contribution to the reorganization energy being $D_{b}$, the bond dissociation energy of the cleaving bond.

$\Delta G^{\neq}=\Delta G_{0}^{\neq}\left(1+\frac{\Delta G^{0}}{4 \Delta G_{0}^{\neq}}\right)^{2}$ with $\Delta G_{0}^{\neq}=\frac{D_{b}+\lambda_{0}}{4}$

$\Delta G^{\neq}$is the free enthalpy of activation, $\Delta G^{0}$ is the standard free enthalpy of the reaction, and $\lambda_{0}$ is the solvent reorganization energy. 


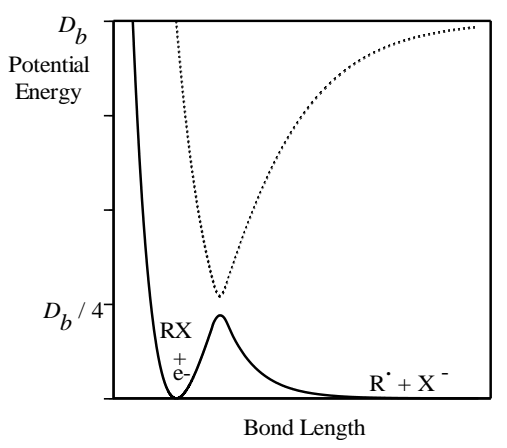

Figure 10. Morse curve model for a concerted dissociative electron transfer.

Application of the model to the homogeneous dissociative electron transfer on alkyl halides ${ }^{111}$ as well as reduction of organic peroxides gives quantitative agreement. ${ }^{112}$ Cyclic voltammetry appears as a very useful tool to identify concerted dissociative electron transfers. Approximating the rate law for a concerted dissociative electron transfer by the classical Butler-Volmer law leads to a transfer coefficient $\alpha=\frac{\partial \Delta G^{\neq}}{\partial \Delta G^{0}}=\frac{1}{2}\left(1+\frac{\Delta G^{0}}{D_{b}+\lambda_{0}}\right)=\sqrt{\frac{\Delta G^{\neq}}{D_{b}+\lambda_{0}}}$. This transfer coefficient is significantly smaller than 0.5 , the typical value for an outersphere electron transfer. Indeed, in cyclic voltammetry, at a given scan rate, the activation free energy at the peak, $\Delta G_{p}^{\neq}$, is given by

$$
\Delta G_{p}^{\neq}=\frac{R T}{F}\left[\ln \left(k_{S} \sqrt{\frac{R T}{\alpha F v D}}\right)-0.78\right]
$$

indicating that its value is roughly similar for both a dissociative and an outersphere electron transfer ( $D$ is the diffusion coefficient of the substrate, $v$ is the scan rate and $k_{S}$ is the standard rate constant for electron transfer). Therefore, because the reorganization energy is much larger for the dissociative process $\left(D_{b}>>\lambda_{i}, \lambda_{i}\right.$ being the internal reorganization energy for outersphere electron transfer), it can be concluded that $\alpha_{\text {dissociative }}<<\alpha_{\text {outersphere }} \approx 0.5$. As the peak width in $\mathrm{CV}$ is given by $E_{p / 2}-E_{p}=1.857 \frac{R T}{\alpha F} \quad\left(E_{p}\right.$ is the peak potential and $E_{p / 2}$ is the potential at the half-wave), it is concluded that the broadness of a wave is a strong criterion for a concerted pathway. This has been illustrated by many examples and it was shown that the molecular structure can control the occurrence of a stepwise or a concerted mechanism (Scheme 6). Among the key factors are the standard potential of the anion radical (low lying $\pi^{*}$ orbital or not), weak or strong bond dissociation energy, oxidability of the leaving group. ${ }^{113,114,115}$ It is worth noting that aryl diazonium cations appear as good candidate for a concerted mechanism. However, their reduction at a glassy carbon electrode leads to derivatization of the electrode via grafting of the generated neutral radical as discovered by Jean Pinson, a longtime collaborator of J-M. Savéant. ${ }^{116}$ Several refinement and extension of the model were pro- posed. One concerns the possible interaction of the dissociated fragments in the solvent cage ( $\sigma$ anion radical) and its effect on the cleavage dynamics. ${ }^{117}$ Other concerns the description of the cleavage step of the $\pi$ anion radical as an intramolecular concerted dissociative electron transfer (see Figure 5 and the corresponding text). ${ }^{58}$

Scheme 6. Dissociative electron transfer

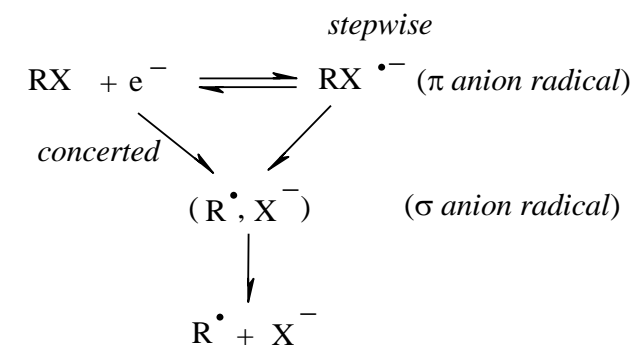

e- : electrode, homogeneous donor (ground state, excited state)

So far, the existence of a concerted mechanism has been intuited from the consideration that the primary radical intermediate following electron transfer lives less than a vibration. In other words, it does not exist. However, an important result from J-M. Savéant work was to show that a transition between stepwise and concerted mechanisms can occur upon changing the driving force as sketched on Figure 11. Again, cyclic voltammetry is a convenient tool to trigger and exemplify this phenomenon as it allows for an easy measurement of the rate of the electrochemical reaction as function of its driving force, which is varied as the electrode potential is scanned. The rate constant can be extracted at any potential using the convolution technique (see first section). Alternatively the rate constant can be measured at the peak potential at various scan rates because, as surprising as it may seem at first sight, increasing the scan rate amounts to change the driving force at the peak potential. Consequently, raising the scan rate in cyclic voltammetry may trigger a transition from a concerted to a stepwise mechanism. ${ }^{119}$

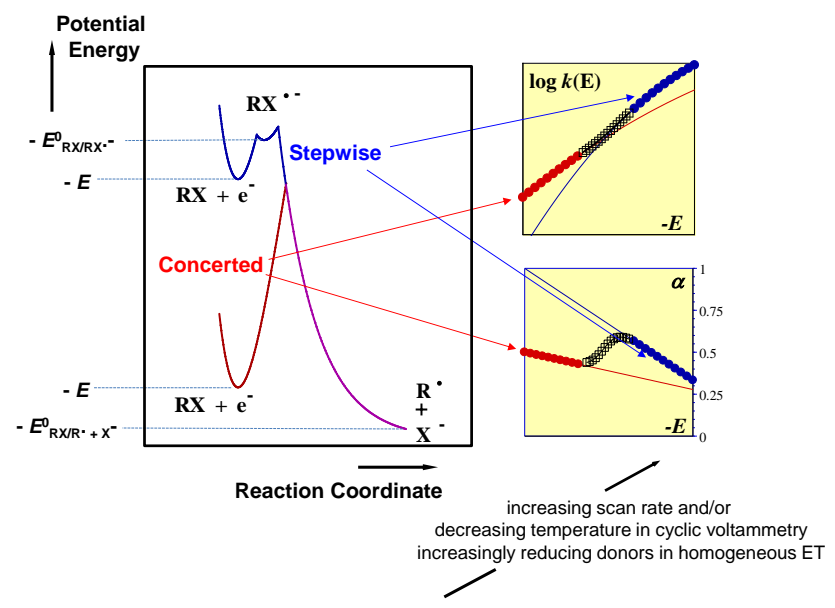

Figure 11. Potential energy profiles for the concerted and stepwise mechanism and variation of the rate constant and the transfer coefficient when passing from the concerted to the stepwise mechanism. Adapted from ref. 118. 
As shown on Figure 11, because outersphere electron transfer and concerted dissociative electron transfers have similar quadratic activation-driving force relationship, but different reorganization energies and different apex, their rate constant $v s$. potential curvature are different and the transition between stepwise and concerted mechanism can be diagnosed from the evolution of the transfer coefficient $\alpha$ as function of potential. Then transition is characterized by an " $\alpha$ wave" which was exemplified experimentally on several systems, ${ }^{119,120}$ not only from J-M. Savéant's group. 121 Transition from concerted to stepwise mechanism upon changing the driving force was also shown in the case of homogeneous reduction of 4-nitrobenzyl and 4-nitrocumyl chlorides. ${ }^{122}$ The very slow rate constant at small driving force was measured thanks to the amplification provided by an $\mathrm{S}_{\mathrm{RN} 1}$ chain process. This was in turn the occasion to explain how thermal $S_{\mathrm{RN} 1}$ reactions discovered by N. Kornblum in 1975 work, thus illustrating the possible role of concerted $v s$. stepwise dissociative electron transfer in organic chemistry. ${ }^{122}$ Remarkably, the concept of concerted dissociative electron transfer has been used in photo-induced electron transfer chemistry and was initially thought as an attractive manner of fighting backelectron transfer to the ground state for systems in which the donor and/or the acceptor in the ion-pair undergoes fragmentation. Intuitively, it seems as an ideal situation that would lead to a unity quantum yield. And thus, a quantum yield below 1 would be the signature of a sequential two-step mechanism. J-M. Savéant and collaborator have shown that a purely dissociative photo-induced electron transfer is in fact not necessarily endowed with a unity quantum yield. ${ }^{123}$ This is related to the fact that the system could partition between and back-electron transfer and cleavage in the funnel offered by the upper first-order potential energy surface combining the ground state and fragments zero-order surfaces. It was an additional illustration of irrigation of a physical chemistry field from concept issued from electron transfer reactivity studied by electrochemistry.

The above description and models apply to the cleavage of bonds between heavy atoms. However, processes involving the cleavage of a bond with an hydrogen, i.e. proton transfer, H-atom transfer (HAT) or proton-coupled electron transfer (PCET) are of utmost importance in chemistry and biology. The question of the competition between electron transfer + proton transfer vs. HAT was investigated by J-M. Savéant as it is in the core of many processes in organic electrochemistry. ${ }^{124} \mathrm{~J}$-M. Savéant was also very interested in investigating $\mathrm{C}-\mathrm{H}$ bond cleavage in particular cation radical deprotonation in collaboration with $\mathrm{J}$. Moiroux. ${ }^{125,126}$ After a first attempt to model such proton transfer reactions, ${ }^{127}$ influenced by the important work of J.T. Hynes, ${ }^{128}$ he took into account that the proton cannot be described classically and then included in the analysis the quantum character of the proton, enabling to reconsider the concept of imbalance of proton transfer. ${ }^{129}$ It is worth noting that this concept, also named principle of imperfect synchronization, was recently reactivated at the occasion of a remarkably study of $\mathrm{C}-\mathrm{H}$ oxidation of substituted fluorenyl-benzoates. ${ }^{130} \mathrm{~J}$-M Savéant showed in his very last published paper that the data can be rather ra- tionalized via a transition between concerted and stepwise mechanisms upon changing the driving force as developed in the dissociative electron transfer context. ${ }^{131}$ Investigation of the intimate pathways for PCET involving different sites for proton transfer and electron transfer, which is the typical case for an electrochemical PCET, indeed bears some similarities with dissociative electron transfer as it required to identify criteria able to discriminate between stepwise and concerted processes (Scheme 7).

Scheme 7. Proton Coupled Electron Transfer, concerted (black) and sequential (grey) pathways.

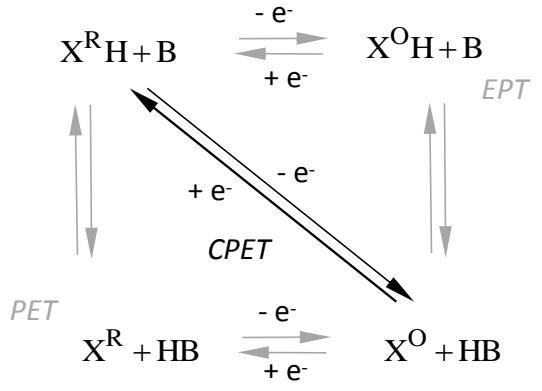

However, in most cases, differences are at least twofold: (i) proton transfer are often fast and at equilibrium, (ii) the kinetic model describing the concerted pathway cannot be akin to the Morse curve model due to the quantum character of the transferring proton. Thus, J-M. Savéant and coworkers proposed a kinetic model for electrochemical concerted proton coupled electron transfer (CPET) based on a double Born-Oppenheimer type approximation which treats the electron as a fast sub-system with respect to the proton and the proton as a fast sub-system with respect to heavy-atoms displacements (Figure 12).132

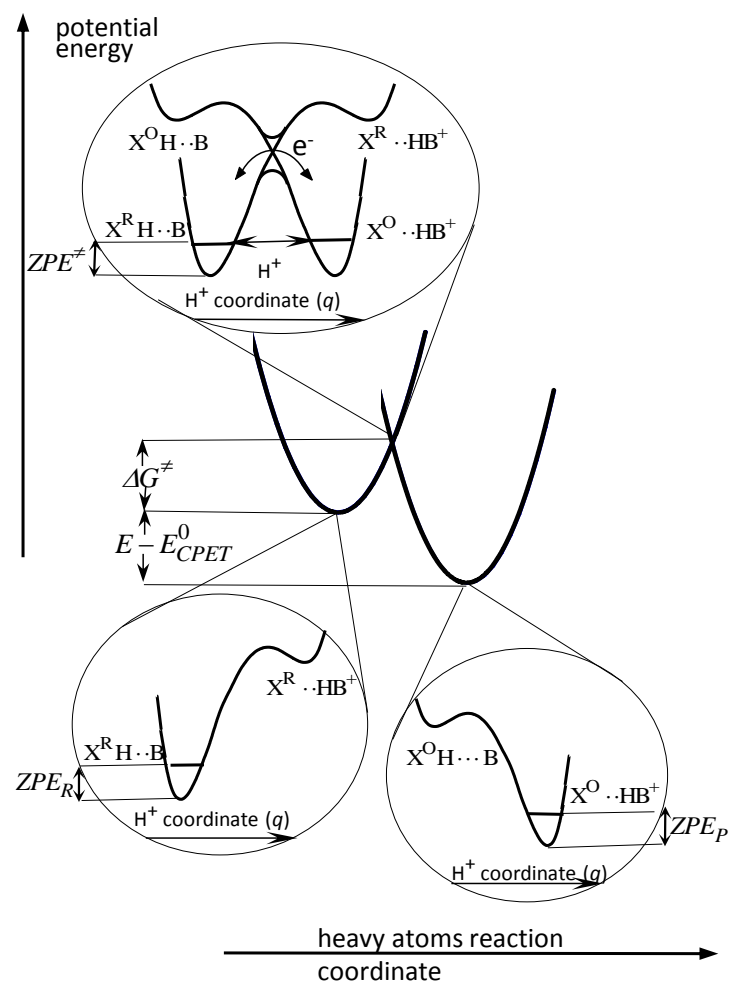


Figure 12. CPET mechanism. Both reactants and product electronic state potential energies as a function of heavyatoms reaction coordinate are described by parabolas. Inserts show potential energies as a function of proton coordinate. Adapted from ref. 132.

Several experimental examples identifying CPET pathways have been reported both in organic solvent ${ }^{133}$ and in water. ${ }^{134}$ In the later, it is important to mention that the role of water as proton acceptor has been scrutinized in details, combining electrochemical ${ }^{135}$ and photoinduced ${ }^{136}$ approaches, and that the notion of $\mathrm{pH}$-dependent driving force was showed to be incorrect. $^{73}$

A further step was achieved when it was shown experimentally that both CPET and dissociative electron transfer can combined in a single step making the cleavage of a bond upon reduction beneficial of the whole driving force of the reaction thanks to an appending acid-base function (Figure 13). ${ }^{137}$ The role of appending acid-base functionalities as proton relays has been widely developed in the context of molecular catalysis and J-M. Savéant, in his never-ending quest for rational analysis, recently provided a kinetic description of the origin and limitations of boosting effects. ${ }^{138}$
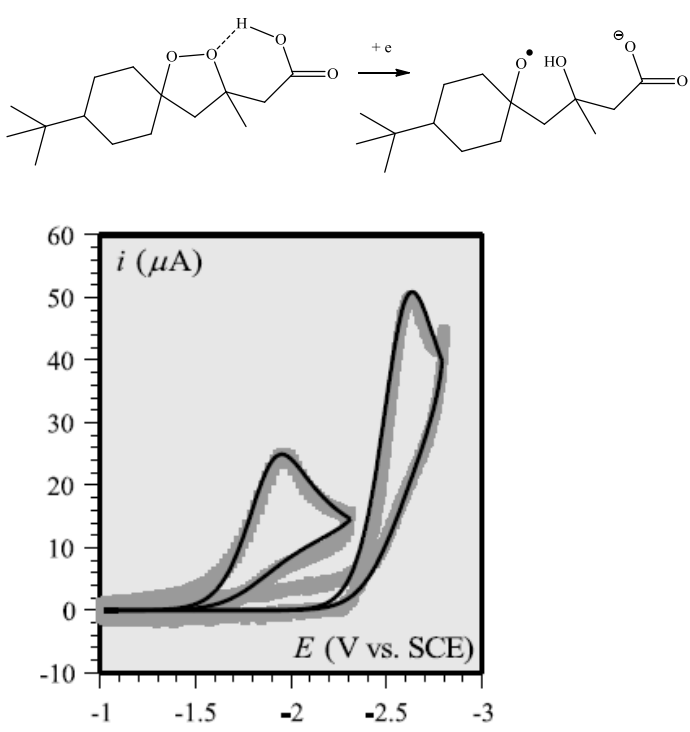

Figure 13. Thick gray lines: cyclic voltammetry of $2 \mathrm{mM}$ the compound shown above (left) and the corresponding ester (right) in DMF at $0.2 \mathrm{~V} / \mathrm{s}$, at a glassy carbon disk electrode. Black thin lines: simulations. Adapted from ref. 137.

Finally as an emblematic example, we would like to mention the demonstration that an all concerted heavy atoms bond intramolecular dissociative CPET is at play in the catalytic process of $\mathrm{CO}_{2}$ to $\mathrm{CO}$ conversion with iron porphyrins in the presence of Brønsted acids. ${ }^{139}$ This would not have been possible without the patient establishment and illustration of various concepts by J-M. Savéant and coworkers over decades. This example shows how the concepts assemble to each other to enlighten complex systems.

\section{Conclusion}

Prof. Jean-Michel Savéant was a giant of electrochemistry.
With an over sixty years career, his legacy in the field is huge and he can be considered as one of the fathers of molecular electrochemistry. Besides, we think that the various, but not exhaustive, examples shown in this review illustrate how J-M. Savéant work irrigates many fields of physical chemistry such as photochemistry and material sciences, biochemistry, radical chemistry and synthetic chemistry including electron transfers, as well as all facets of catalysis where molecules play a role. The extreme rigor of the studies combined to the formal description of the electrochemical systems under investigation are the real two pillars of the apparent simplicity and elegance of J-M. Savéant work. Along with well-chosen illustrative experimental examples it has allowed to feed the establishment of structure-reactivity relationships and a thorough understanding of intimate reactivity at the molecular scale. It will remain a strong source of inspiration for all scientists interest by electron transfer chemistry.

\section{AUTHOR INFORMATION}

\section{Corresponding Authors}

cyrille.costentin@univ-grenoble-alpes.fr

limoges@u-paris.fr

robert@u-paris.fr

cedric.tard@polytechnique.edu

\section{Notes}

The author declares no competing financial interest. REFERENCES

(1) (a) Savéant, J-M. Elements of Molecular and Biomolecular Electrochemistry, John Wiley \& Sons, Inc., Hoboken, NJ, USA, 2006 (b) Savéant, J-M.; Costentin, C. Elements of Molecular and Biomolecular Electrochemistry, 2nd Ed; John Wiley \& Sons, Inc., Hoboken, NJ, USA, 2019.

(2) Savéant, J-M. Professor Elio Vianello - Obituary. J. Electroanal. Chem. 1998, 453, 3-8.

(3) Nicholson, R. S.; Shain, I. Theory of Stationnary Electrode Polarography. Single Scan and Cyclic Methods Applied to Reversible, Irreversible, and Kinetic Systems. Anal. Chem. 1964, 36, 706723.

(4) Savéant, J-M.; Vianello, E. Potential-Sweep Voltammetry. General theory of Chemical Polarization. Electrochim. Acta. 1967, 12, 629-646.

(5) Andrieux, C. P.; Savéant, J-M. Formation de Cations Immonium par Oxydation Anodique d'Amines Aliphatiques. Bull. Soc. Chim. 1969, 4, 1254-1256.

(6) Andrieux, C. P.; Nadjo, L.; Savéant, J-M. J. Electroanal. Chem. 1970, 26, 147-186.

(7) Mastragostino, M.; Nadjo, L.; Savéant, J-M. Disproportionation and ECE Mechanisms- I. Theoretical Analysis. Relationships for Linear Sweep Voltammetry. Electrochim. Acta. 1968, 13, 721-749. (8) Mastragostino, M.; Savéant, J-M. Disproportionation and ECE Mechanisms- II. Reduction of the Uranyl Cation in Perchloric Acid. Electrochim. Acta. 1968, 13, 751-762.

(9) Amatore, C.; Savéant, J-M. ECE and Disproportionation. Part V. Stationary State General Solution Application to Linear Sweep Voltammetry. J. Electroanal. Chem. 1977, 85, 27-46.

(10) Amatore, C.; Savéant, J-M. ECE and Disproportionation. Part VI. General Resolution. Application to Potential Step Chronoamperometry. J. Electroanal. Chem. 1979, 102, 21-40. 
(11) Nadjo, L.; Savéant, J-M. Disproportionation and ECE Mechanisms- III. Asymmetrical Potential-Scan Method: Diagnostic Criteria and Rate-Determination Procedures and Application to the Reduction Mechanism of the Uranyl Cation in Perchloric Acid. Electrochim. Acta. 1971, 16, 887-900.

(12) Savéant, J-M.; Andrieux, C. P.; Nadjo, L. Disproportionation and ECE Mechanisms- IV. Reversible E.C.E. Process. J. Electroanal. Chem. 1973, 41, 137-1410.

(13). Amatore, C.; Gareil, M.; Savéant, J-M. Kinetics of the Protonation of Anthracene Anion Radical by Phenol in Dimethylformamide. J. Electroanal. Chem. 1984, 176, 377-382.

(14). Andersen, M. L.; Wayner, D. D. M. Electrochemistry of Electron Transfer Probes. Competition between ECE and DISP Mechanisms in the Reduction of $\alpha$-Aryloxyacetophenones J. Electroanal. Chem. 1996, 412, 53-58.

(15). Amatore, C.; Lexa, D.; Savéant, J-M. ECE Reaction Pathways in the Electrochemical Pathways in the Electrochemical Reduction of Dicyanocobalamin. Kinetics of Ligand Substitution in Vitamin B12r Cyanocob(II)alamin. J. Electroanal. Chem. 1980, 111, 81-89.

(16) (a) Marcus, R. A. On the Theory of Oxidation-Reduction Reactions Involving Electron Transfer. I. J. Chem. Phys. 1956, 24, 966978. (b) Marcus, R. A. On the Theory of Electron-Transfer Reactions. VI. Unified Treatment for Homogeneous and Electrode Reactions. J. Chem. Phys. 1965, 43, 679-701. (c) Hush, N. S. Adiabatic Rate Processes at Electrodes. I. Energy-Charge Relationships. J. Chem. Phys. 1958, 28, 962-972.

(17) Imbeaux, J. C.; Savéant, J-M. Convolutive Potential Sweep Voltammetry. I. Introduction. J. Electroanal. Chem. 1973, 44, 169187.

(18) Ammar, F.; Savéant, J-M. Convolution Potential Sweep Voltammetry. II. Multistep Nernstian Waves. J. Electroanal. Chem. 1973, 47, 215-221.

(19) Nadjo, L.; Savéant, J-M.; Tessier, D. Convolution Potential Sweep Voltammetry. III. Effect of Sweep Rate Cyclic Voltammetry. J. Electroanal. Chem. 1974, 52, 403-412.

(20) Savéant, J-M. ; Tessier, D. Convolution Potential Sweep Voltammetry. Part IV. Homogeneous Follow-up Chemical Reactions. J. Electroanal. Chem. 1975, 61, 251-263.

(21) Note that a similar method was developed at the same time by Oldham and Grenness but not in the purpose of mechanism analysis. (a) Oldham, K., B. Anal. Chem. 1972, 44, 196. (a) Grenness, M.; Oldham, K. B. Anal. Chem. 1972, 44, 1121.

(22) Savéant, J-M. Effect of the Electrode Continuum of States in Adiabatic and Nonadiabatic Outer-Sphere and Dissociative Electron Transfers. Use of Cyclic Voltammetry for Investigating Nonlinear Activation-Driving Force Laws. J. Phys. Chem. B 2002, 106, 9387-9395.

(23) Savéant, J-M. ; Tessier, D. Convolution Potential Sweep Voltammetry. V. Determination of Charge Transfer Kinetics Deviating From the Butler-Volmer Behaviour. J. Electroanal. Chem. 1975, 65, 57-66.

(24) Savéant, J-M. ; Tessier, D. Convolution Potential Sweep Voltammetry. Part VI. Experimental Evaluation in the Kilovolt per Second Sweep Rate Range. J. Electroanal. Chem. 1977, 77, 225235.

(25) Garreau, D.; Savéant, J-M. Linear Sweep Voltammetry - Compensation of Cell Resistance and Stability. J. Electroanal. Chem. 1972, 35, 309-331.

(26) Garreau, D.; Hapiot, P. ; Savéant, J-M. Intrumentation for Fast Voltammetry at Ultramicroelectrodes. Stability and Bandpass Limitations. J. Electroanal. Chem. 1989, 272, 1-16.

(27) Hapiot, P.; Konovalov, V. V.; Savéant, J.-M., Application of laser pulse photoinjection of electrons from metal electrodes to the determination of reduction potentials of organic radicals in aprotic solvents. J. Am. Chem. Soc. 1995, 117, 1428-1434.

(28) Andrieux, C. P. ; Hapiot, P. ; Pinson, J. ; Savéant, J-M. Determination of Formal Potentials of Chemically Unstable Redox Couples by Second-Harmonic Alternating Current Voltammetry and Cyclic Voltammetry. Application to the Oxidation of Thiophenoxide Ions. J. Am. Chem. Soc. 1993, 115, 7783-7788.

(29) Studer, A. ; Curran, D. P. The Electron is a Catalyst. Nat Chem. 2014, 6, 765-773.

(30) Savéant, J-M. Catalysis of Chemical Reactions by Electrodes. Acc. Chem. Res. 1980, 13, 323-329.

(31) Bunnett, J. F. Substitution by the $\mathrm{S}_{\mathrm{RN}} 1$ Mechanism. Acc. Chem. Res. 1978, 11, 413-419.

(32) Note that the situation can be different if the product anion radical is stable at the level of the substrate reduction wave. See ref. 30 .

(33) Amatore, C.; Savéant, J-M. Product Distribution in Preparative Scale Electrolysis. Part I. Introduction. J. Electroanal. Chem. 1981, 123, 189-201.

(34) Amatore, C.; Savéant, J-M. Product Distribution in Preparative Scale Electrolysis. Part II. EC Reaction Schemes Followed by Competition between First-Order Chemical Reaction and further Electron Transfer. One-Electron Systems. J. Electroanal. Chem. 1981, 123, 203-217.

(35) Amatore, C.; M'Halla, F.; Savéant, J-M. Product Distribution in Preparative Scale Electrolysis. Part III. EC Reaction Schemes Followed by Competition between First-Order Chemical Reaction and further Electron Transfer. Two-Electron Systems. J. Electroanal. Chem. 1981, 123, 219-229.

(36) Amatore, C.; Pinson, J.; Savéant, J-M. Product Distribution in Preparative Scale Electrolysis. Part IV. EC Reaction Schemes Followed by Competition between First-Order Chemical Reaction and further Electron Transfer. Electrocatalytic Systems. J. Electroanal. Chem. 1981, 123, 189-201.

(37) Amatore, C.; Savéant, J-M. Product Distribution in Preparative Scale Electrolysis. Part V. EC Reaction Schemes Followed by Competition Dimerization and First-Order Deactivation or further Electron Transfer. J. Electroanal. Chem. 1981, 125, 1-21.

(38) Amatore, C.; Savéant, J-M. Product Distribution in Preparative Scale Electrolysis. Part VI. Competition between Dimerization and First-Order Deactivation. J. Electroanal. Chem. 1981, 125, 2339.

(39) Amatore, C.; Savéant, J-M. Product Distribution in Preparative Scale Electrolysis. Part VII. Competition at the Level of the First-Electron Intermediate between Self-Coupling, Coupling with the Substrate and First-Order Deactivation Followed by further Electron Transfer J. Electroanal. Chem. 1981, 126, 1-19.

(40) Savéant, J-M. Product Distribution in Preparative Scale Electrolysis. Part VIII. Transition Between Fast and Slow Chemical Kinetics. Application to Mechanisms Involving One or Two FirstOrder Consecutive Chemical Steps J. Electroanal. Chem. 1987, 236, 31-42.

(41) Gennaro, A.; Isse, A. A.; Severin, M-A.; Vianello, E.; Bhugun, I.; Savéant, J-M. Mechanism of the Electrochemical Reduction of Carbon Dioxide at Inert Electrodes in Media of Low Proton Availability. J. Chem. Soc. Faraday Trans.. 1996, 92, 3963-5021.

(42) Wiebe, A.; Gieshoff, T.; Möhle, S.; Rodrigo, E.; Zirbes, M.; Waldvogel, S. R. Electrifying Organic Synthesis. Angew. Chem. Int. Ed. 2018, 57, 5594-5619.

(43) Savéant, J-M., Vianello, E. Recherche sur les courants catalytiques en polarographie oscillographique à balayage linéaire de tension. in Advances in Polarography, I. S. Longmuir, ed., Vol. 1, Pergamon Press, New York, 1959, p. 367-374.

(44) Savéant, J-M. ; Vianello, E. Potential-Sweep Chronoamperometry : Kinetic Currents for First-Order Chemical Reaction Parallel to Electron-Transfer Process (Catalytic Currents). Electrochim. Acta. 1965, 10, 905-920.

(45) Andrieux, C. P.; Dumas-Bouchiat, J-M.; Savéant, J-M. Homogeneous Redox Catalysis of Electrochemical Reactions. Part I. Introduction. J. Electroanal. Chem. 1978, 87, 39-53. 
(46) Andrieux, C. P.; Dumas-Bouchiat, J-M.; Savéant, J-M. Homogeneous Redox Catalysis of Electrochemical Reactions. Part II. Rate Determining Electron Transfer. Evaluation of Rate and Equilibrium Parameters. J. Electroanal. Chem. 1978, 87, 55-65.

(47) Andrieux, C. P.; Dumas-Bouchiat, J-M.; Savéant, J-M. Homogeneous Redox Catalysis of Electrochemical Reactions. Part III. Rate Determining Electron Transfer. Kinetic Characterization of Follow-up Chemical Reactions. J. Electroanal. Chem. 1978, 88, 43-48.

(48) Andrieux, C. P.; Dumas-Bouchiat, J-M.; Savéant, J-M. Homogeneous Redox Catalysis of Electrochemical Reactions. Part IV. Kinetic Controls in the Homogeneous Process as Characterized by Stationnary and Quasi-Stationnary Electrochemical Techniques. J. Electroanal. Chem. 1980, 113, 1-18.

(49) Andrieux, C. P.; Blocman, C. ; Dumas-Bouchiat, M'Halla, F. ; JM.; Savéant, J-M. Homogeneous Redox Catalysis of Electrochemical Reactions. Part V. Cyclic Voltammetry. J. Electroanal. Chem. 1980, 113, 19-40.

(50) Savéant, J-M; Su, K. B. Homogeneous Redox Catalysis of Electrochemical Reactions. Part VI. Zone Diagram Representation of the Kinetic Regimes. J. Electroanal. Chem. 1984, 171, 341-349.

(51) Savéant, J-M. Molecular Catalysis of Electrochemical Reactions. Mechanistic Aspects. Chem. Rev. 2008, 108, 2348-2378.

(52) see for example: (a) Simonet, J.; Michel M-A.; Lund H. Indirect Electrolysis. Reaction between Alkyl Halides and Electrolytically Generated Anion Radicals. Acta Chem. Scandi. B 1975, 29, 489498. (b) Lund, H. Catalysis by Electron Transfer Reagents in Organic Electrochemistry. J. Mol. Catal. 1986, 38, 203-226.

(53) Andrieux, C. P.; Anne, A. ; Moiroux, J. ; Savéant, J-M. Homogeneous Redox Catalysis of Electrochemical Reactions. Application to the Kinetic Characterization of Intermediates Undergoing Fast Bimolecular Decay Approaching the Diffusion Limit. J. Electroanal. Chem. 1991, 307, 17-28.

(54) Andrieux, C. P.; Savéant, J-M. Homogeneous Redox Catalysis of Electrochemical Reactions. Electron Transfers Followed by a Very Fast Chemical Step. J. Electroanal. Chem. 1986, 205, 43-58.

(55) Andrieux, C. P.; Hapiot, P.; Savéant, J-M. Fast Kinetics by Means of Direct and Indirect Electrochemical Techniques. Chem. Rev. 1990, 905, 723-738.

(56) Andrieux, C. P.; Blocman, C. ; Dumas-Bouchiat, J-M. ; M'Halla, F. ; Savéant, J-M. Determination of the Lifetimes of Unstable Ion Radicals by Homogeneous Redox Catalysis of Electrochemical Reactions. Application to the Reduction of Aromatic Halides. J. Am. Chem. Soc. 1980, 102, 3806-3813.

(57) (a) Evans, M. G.; Hush, N. S. Ionogenic Reactions Involving Bond Breaking at Electrodes. J. Chim. Phys. 1952, 49, C159-C171. (b) Hush, N. S. Electrode Reactions of the Methyl Halides. Z. Elecktrochem. 1957, 61, 734-738.

(58) Costentin, C.; Robert, M.; Savéant, J-M. Fragmentation of Aryl Halides $\mathrm{p}$ Anion Radicals. Bending of the Cleaving Bond and Activation vs Driving Force Relationships. J. Am. Chem. Soc. 2004, 126, 16051-16057.

(59) Lexa, D.; Savéant, J-M.; Schäfer, H. J. ; Su K-B. ; Vering, B. ; Wang, D. L. Outer-Sphere and Inner-Sphere Processes in Reductive Elimination. Direct and Indirect Electrochemical Reduction of Vicinal Dibromoalkanes. J. Am. Chem. Soc. 1990, 112, 6162-6177.

(60) Lexa, D.; Savéant, J-M. The electrochemistry of vitamin B12. Acc. Chem. Res. 1983, 16, 235-243.

(61) Steckhan, E. Indirect Electroorganic Syntheses - A Modern Chapter of Organic Electrochemistry. Angew. Chem. Int. Ed. 1986, $25,683-701$.

(62) Hammouche, M.; Lexa, D.; Momenteau, M.; Savéant, J-M Catalysis of the Electrochemical Reduction of Carbon Dioxide by Iron("0") Porphyrins. J. Electroanal. Chem. 1988, 249, 347-351.

(63) Hammouche, M.; Lexa, D.; Momenteau, M.; Savéant, J-M. Chemical Catalysis of Electrochemical Reactions. Homogeneous Catalysis of the Electrochemical Reduction of Carbon Dioxide by
Iron("0") Porphyrins. Role of the Addition of Magnesium Cations. J. Am. Chem. Soc. 1991, 113, 8455-8466.

(64) Amatore, C.; Savéant, J-M. Mechanism and Kinetic Characteristics of the Electrochemical Reduction of Carbon Dioxide in Media of Low Proton Availability. J. Am. Chem. Soc. 1981, 103, 50215023.

(65) Lamy, E.; Nadjo, L.; Savéant, J-M. Standard Potential and Kinetic Parameters of the Electrochemical Reduction of Carbon Dioxide in Dimethylformamide. J. Electroanal. Chem. 1977, 78, 403-407.

(66) Costentin, C.; Drouet, S. ; Robert, M. ; Savéant, J-M. Turnover Numbers, Turnover Frequencies, and Overpotential in Molecular Catalysis of Electrochemical Reactions. Cyclic Voltammetry and Preparative-Scale Electrolysis. J. Am. Chem. Soc. 2012, 134, 1123511242.

(67) Bhugun, I.; Lexa, D. ; Savéant, J-M. Catalysis of the Electrochemical Reduction of Carbon Dioxide by Iron(0) Porphyrins: Synergystic Effect of Weak Brönsted Acids. J. Am. Chem. Soc. 1996, $118,1769-1776$

(68) Costentin, C.; Drouet, S. ; Robert, M. ; Savéant, J-M. A Local Proton Source Enhances $\mathrm{CO}_{2}$ Electroreduction to $\mathrm{CO}$ by a Molecular Fe Catalyst. Science 2012, 338, 90-94.

(69) Azcarate, I. ; Costentin, C.; Robert, M. ; Savéant, J-M. Dissection of Electronic Substituent Effects in Multielectron-Multistep Molecular Catalysis. Electrochemical $\mathrm{CO}_{2}$-to-CO Conversion Catalyzed by Iron Porphyrins. J. Phys. Chem. C 2016, 120, 2895128960.

(70) Azcarate, I. ; Costentin, C.; Robert, M. ; Savéant, J-M. ThroughSpace Charge Interaction Substituents Effects in Molecular Catalysis Leading to the Design of the Most Efficient Catalyst of $\mathrm{CO}_{2}$-toCO Electrochemical Conversion. J. Am. Chem. Soc. 2016, 138, 16639-16644

(71) Costentin, C.; Savéant, J-M. Tard, C. Catalysis of $\mathrm{CO}_{2}$ Electrochemical Reduction by Protonated Pyridine and Similar Molecules. Useful Lessons from a Methodological Misadventure. ACS Energy. Lett. 2018, 3, 695-703.

(72) Costentin, C.; Savéant, J-M. Homogeneous Molecular Catalysis of Electrochemical Reactions. Manipulating Intrinsic and Operational Factors for Catalyst Improvement. J. Am. Chem. Soc. 2018, $140,16669-16675$.

(73) Costentin, C.; Robert, M. ; Savéant, J-M. Concerted ProtonElectron Transfer Reactions in Water. Are the Driving Force and Rate Constant Depending on $\mathrm{pH}$ When Water Acts as Proton Donor or Acceptor? J. Am. Chem. Soc. 2007, 129, 5870-5879.

(74) Costentin, C.; Passard, G.; Robert, M.; Savéant, J-M. Pendant Acid-Base Groups in Molecular Catalysts: H-Bond Promoters or Proton Relays? Mechanism of the Conversion of $\mathrm{CO}_{2}$ to $\mathrm{CO}$ by Electrogenerated Iron(0)Porphyrins Bearing Prepositioned Phenol Functionalities. J. Am. Chem. Soc. 2014, 136, 11821-11829.

(75) Amatore, C.; Savéant, J-M.; Tessier, D. Charge Transfer at Partially Blocked Surfaces. A Model for the Case of Microscopic Active and Inactive Sites. J. Electroanal. Chem. 1983, 147, 39-51.

(76) Andrieux, C. P.; Savéant, J-M. Heterogeneous (Chemically Modified Electrodes, Polymer Electrodes) vs. Homogeneous Catalysis of Electrochemical Reactions. J. Electroanal. Chem. 1978, 93, 163-168.

(77) Savéant, J-M. Electron Hopping Between Fixed Sites. Equivalent Diffusion and Migration Laws. J. Electroanal. Chem. 1986, 201, 211-213.

(78) Blauch, D. N.; Savéant, J-M. Dynamics of Electron Hopping in Assemblies of Redox Centers. Percolation and Diffusion. J. Am. Chem. Soc. 1992, 114, 3323-3332.

(79) De Levie, R. On Porous Electrodes in Electrolyte Solutions : I. Capacitance Effects. Electrochim. Acta 1963, 8, 751-780.

(80) Andrieux, C. P. ; Costentin, C. ; Di Giovanni, C.; Savéant, J-M. ; Tard, C. Conductive Mesoporous Catalytic Films. Current Distortion and Performance Degradation by Dual-Phase Ohmic Drop 
Effects. Analysis and Remedies. J. Phys. Chem. C 2016, 120, 2126321271.

(81) Costentin, C. ; Savéant, J-M. Energy Storage : Pseudocapacitance in Prospect. Chem. Sci. 2019, 10, 5656-5666.

(82) Andrieux, C. P.; Dumas-Bouchiat, J-M. ; Savéant, J-M. Catalysis of Electrochemical Reactions at Derivatized Electrodes. Kinetic Model for Stationary Voltammetric Techniques and Preparative Scale Electrolysis. J. Electroanal. Chem. 1980, 123, 171-187.

(83) Andrieux, C. P.; Dumas-Bouchiat, J-M. ; Savéant, J-M. Catalysis of Electrochemical Reactions at Redox Polymer Electrodes. Effect of the Film Thickness. J. Electroanal. Chem. 1980, 114, 159-163.

(84) Andrieux, C. P.; Savéant, J-M. Kinetics of Electrochemical Reactions Mediated by Redox Polymer Films. Reversible CrossExchange Reactions. J. Electroanal. Chem. 1982, 142, 1-30.

(85) Andrieux, C. P.; Dumas-Bouchiat, J-M. ; Savéant, J-M. Catalysis of Electrochemical Reactions at Redox Polymer Electrodes. Kinetic Model for Stationary Voltammetric Techniques. J. Electroanal. Chem. 1982, 131, 1-35.

(86) Andrieux, C. P.; Savéant, J-M. Kinetics of Electrochemical Reactions Mediated by Redox Polymer Films. Irreversible CrossExchange Reactions: Formulation in Terms of Characteristic Currents for Stationnary Techniques. J. Electroanal. Chem. 1982, 134, 163-166.

(87) Andrieux, C. P.; Dumas-Bouchiat, J-M.; Savéant, J-M. Kinetics of Electrochemical Reactions Mediated by Redox Polymer Films. New Formulation and Strategies For Analysis and Optimization. J. Electroanal. Chem. 1984, 169, 9-21.

(88) Andrieux, C. P.; Savéant, J-M. Kinetics of Electrochemical Reactions Mediated by Redox Polymer Films. Pre-Activation (CE) Mechanisms. J. Electroanal. Chem. 1984, 171, 65-93.

(89) Costentin, C. ; Savéant, J-M. Cyclic Voltammetry Analysis of Electrocatalytic Films. J. Phys. Chem. C 2015, 119, 12174-12182.

(90) Costentin, C. ; Savéant, J-M. Cyclic Voltammetry of Fast Conducting Electrocatalytic Films. Phys. Chem. Chem. Phys. 2015, 17, 19350-19359.

(91) Costentin, C.; Savéant, J-M. Cyclic Voltammetry of Electrocatalytic Films: Fast Catalysis Regimes. ChemElectroChem 2015, 2, 1774-1784.

(92) Anson, F. C. ; Savéant, J-M. ; Shigehara, K. Kinetics of Mediated Electrochemical Reactions at Electrodes Coated with Redox Polymer Films. J. Electroanal. Chem. 1983, 145, 423-430.

(93) Anson, F. C. ; Tsou, Y-M.; Savéant, J-M. Outer-sphere Oxidation of Ascorbate with Os(bpy) $3^{3+}$ Incorporated in Nafion Coatings on Graphite Electrodes. J. Electroanal. Chem. 1984, 178, 113-127.

(94) Anson, F. C. ; Ni, C-L.; Savéant, J-M. Electrocatalysis at Redox Polymer Electrodes with Separation of the Catalytic and Charge Propagation Roles. Reduction of $\mathrm{O}_{2}$ to $\mathrm{H}_{2} \mathrm{O}_{2}$ as Catalyzed by Cobalt(II)Tetrakis(4- $N$-methylpyridyl)porphyrin. J. Am. Chem. Soc. 1985, 107, 3442-3450.

(95) Leddy, J. ; Bard, A. J.; Maloy, J. T.; Savéant, J-M. Kinetics of Film-Coated Electrodes. Effect of a Finite Mass Transfer Rate of Substrate across the Film-Solution Interface at Steady State. J. Electroanal. Chem. 1985, 187, 205-227.

(96) Carbon Dioxide Electrochemistry: Homogeneous and Heterogeneous Catalysis. RSC, 2021.

(97) Savéant, J-M. Jacques Moiroux (1943-2002) - Obituary. J. Electroanal. Chem. 2002, 529, 79-83.

(98) Anne, A. ; Moiroux, J. ; Savéant, J-M. Formal Hydride Transfer from NADH Analogues. 1-Benzyl-4-tert-butyl-1,4dihydronicotinamide as a Mechanistic Probe. J. Am. Chem. Soc. 1993, 115, 10224-10230.

(99) Limoges, B. ; Moiroux, J. ; Savéant, J-M. Kinetic Control by the Substrate and/or the Cosubstrate in Electrochemically Monitored Redox Enzymatic Homogeneous Systems. Catalytic Responses in Cyclic Voltammetry. J. Electroanal. Chem. 2002, 521, 1-7.

(100) Bourdillon, C. ; Demaille, C. ; Moiroux, J. ; Savéant, J-M. New Insights into the Enzymatic Catalysis of the Oxidation of Glucose by Native and Recombinant Glucose Oxidase Mediated by Electrochemically Generated One-Electron Redox Cosubstrates. J. Am. Chem. Soc. 1993, 115, 2-10.

(101) Dequaire, M. ; Limoges, B. ; Moiroux, J. ; Savéant, J-M. Mediated Electrochemistry of Horseradish Peroxidase. Catalysis and Inhibition. J. Am. Chem. Soc. 2002, 124, 240-253.

(102) Durand, F. ; Limoges, B. ; Mano, N. ; Mavré, F. ; MirandaCastro, R. ; Savéant, J-M. Effect of Substrate Inhibition and Cooperativity on the Electrochemical Responses of Glucose Dehydrogenase. Kinetic Characterization of Wild and Mutant Types. J. Am. Chem. Soc. 2011, 133, 12801-12809.

(103) Limoges, B. ; Moiroux, J. ; Savéant, J-M. Kinetic Control by the Substrate and the Cosubstrate in Electrochemically Monitored Redox Enzymatic Immobilized Systems. Catalytic Responses in Cyclic Voltammetry and Steady State Techniques. J. Electroanal. Chem. 2002, 521, 8-15.

(104) Bourdillon, C. ; Demaille C. ; Gueris, J. ; Moiroux, J. ; Savéant, J-M. A fully active monolayer enzyme electrode derivatized by antigen-antibody attachment J. Am. Chem. Soc. 1993, 115, 26, 12264-12269.

(105) Limoges, B. ; Marchal, D. ; Mavré, F. ; Savéant J-M. Electrochemistry of Immobilized Redox Enzymes: Kinetic Characteristics of NADH Oxidation Catalysis at Diaphorase Monolayers Affinity Immobilized on Electrodes. J. Am. Chem. Soc., 2006, 128, 20842092

(106) Bourdillon, C. ; Demaille, C.; Moiroux, J. ; Savéant, J-M. Catalysis and Mass Transport in Spatially Ordered Enzyme Assemblies on Electrodes. J. Am. Chem. Soc., 1995, 117, 11499-11506.

(107) Andrieux, C. P.; Limoges, B.; Savéant, J-M.; Yazidi, D. Cyclic Voltammetric Responses pf Horseradish Peroxidase Multilayers on Electrodes. Langmuir. 2006, 22, 10807-10815.

(108) Sprague, E. D.; Williams, F. ESR Observation of Methyl Radical-Halide Ion Pairs Produced by Dissociative Electron Capture in a Crystalline Matrix. J. Chem. Phys. 1971, 54, 5425-5427.

(109) Andrieux, C. P. ; Merz, A. ; Savéant, J-M. Dissociative Electron Transfer. Autocatalysis and Kinetic Characteristics of the Electrochemical Reductive Cleavage of the Carbon-Halogen Bond in Alkyl Halides Giving Rise to Stable Radicals and Carbanions. J. Am. Chem. Soc. 1985, 107, 6097-6103.

(110) Andrieux, C. P. ; Gallardo, I. ; Savéant, J-M. ; Su, K-B. Dissociative Electron Transfer. Homogeneous and Heterogeneous Reductive Cleavage of the Carbon-Halogen Bond in Simple Aliphatic Halides. J. Am. Chem. Soc. 1986, 108, 647-654.

(111) Savéant, J-M. A Simple Model for the Kinetics of Dissociative Electron Transfer in Polar Solvents. Application to the Homogeneous and Heterogeneous Reduction of Alkyl Halides. J. Am. Chem. Soc. 1987, 109, 6788-6795.

(112) Workentin, M. S.; Maran, F.; Wayner, D. D. M. Reduction of Di-tert-Butyl Peroxide: Evidence for Nonadiabatic Dissociative Electron Transfer. J. Am. Chem. Soc. 1995, 117, 2120-2121.

(113) Andrieux, C. P.; Le Gorande, A.; Savéant, J-M. Electron Transfer and Bond Breaking. Examples of Passage from a Sequential to a Concerted Mechanism in the Electrochemical Reductive Cleavage of Arylmethyl Halides. J. Am. Chem. Soc. 1992, 114, 68926904.

(114) Andrieux, C. P.; Differding, E.; Robert, M.; Savéant, J-M. Controlling Factors of Stepwise Versus Concerted Reductive Cleavages. Illustrative Examples in the Electrochemical Reductive Breaking of Nitrogen-Halogen Bonds in Aromatic N-Halosultams. J. Am. Chem. Soc. 1993, 115, 6592-6599.

(115) Andrieux, C. P.; Savéant, J-M.; Tallec, A.; Tardivel, R.; Tardy, C. Concerted and Stepwise Dissociative Electron Transfers. Oxidability of the Leaving Group and Stength of the Breaking Bond as Mechanism and Reactivity Governing Factors Illustrated by the Electrochemical Reduction of the $\alpha$-Substituted Acetophenones. J. Am. Chem. Soc. 1997, 119, 2420-2429. 
(116) Delamar, M.; Hitmi, R.; Pinso, J.; Savéant-J-M. Covalent Modification of Carbon Surfaces by Grafting of Functionalized Aryl Radicals Produced from Electrochemical Reduction of Diazonium Salts. J. Am. Chem. Soc. 1992, 114, 5883-5884.

(117) Costentin, C. ; Robert, M. ; Savéant, J-M. Stepwise and Concerted Pathways in Thermal and Photoinduced ElectronTransfer/Bond-Breaking Reactions. J. Phys. Chem A 2000, 104, 7492-7501.

(118) Costentin, C.; Robert, M.; Savéant, J-M. Electron transfer and bond breaking. Recent advances. Chem. Phys. 2006, 324, 40-56.

(119) Andrieux, C. P.; Robert, M. ; Saeva, F. D. ; Savéant, J-M. Passage from Concerted to Stepwise Dissociative Electron Transfer as a Function of the Molecular Structure and of the Energy of the Incoming Electron. Electrochemical Reduction of Aryldialkyl Sulfonium Cations. J. Am. Chem. Soc. 1994, 116, 7864-7871.

(120) Pause, L.; Robert, M.; Savéant, J-M. Can Single-Electron Transfer Break an Aromatic Carbon-Heteroatom Bond in One Step? A Novel Example of Transition between Stepwisse and Concerted Mechanisms in the Reduction of Aromatic Iodides. J. Am. Chem. Soc. 1999, 121, 7158-7159.

(121) Antonello, S.; Maran, F. Evidence for the Transition between Concerted and Stepwise Heterogeneous Electron Transfer-Bond Fragmentation Mechanisms. J. Am. Chem. Soc. 1997, 119, 1259512600.

(122) Costentin, C.; Hapiot, P.; Médebielle, M.; Savéant, J-M. "Thermal" SRN $_{1}$ Reactions : How do They Work ? Novel Evidence that the Driving Force Controls the Transition between Stepwise and Concerted Mechanisms in Dissociative Electron Transfers. J. Am. Chem. Soc. 1999, 121, 4451-4461.

(123) Robert, M.; Savéant, J-M. Photoinduced Dissociative Electron Transfer: Is the Quantum Yield Theoretically Predicted to Equal Unity? J. Am. Chem. Soc. 2000, 122, 514-517

(124) M'Halla, F., Pinson, J.; Savéant, J-M. The Solvent as H-Atom Donor in Organic Electrochemistry Reactions. Reduction of Aromatic Halides. J. Am. Chem. Soc. 1980, 102, 4120-4127.

(125) Anne, A. ; Hapiot, P. ; Moiroux, J. ; Neta, P. ; Savéant, J-M. Dynamics of Proton Transfer from Cation Radicals. Kinetic and Thermodynamic Acidities of Cation Radicals of NADH Analogues. J. Am. Chem. Soc. 1992, 114, 4694-4701.

(126) Anne, A. ; Fraoua, S. ; Hapiot, P. ; Moiroux, J. ; Savéant, J-M. Steric and Kinetic Isotope Effects in the Deprotonation of Cation Radicals of NADH Synthetic Analogues. J. Am. Chem. Soc. 1995, $117,7412-7421$.

(127) Anne, A. ; Fraoua, S. ; Grass, V. ; Moiroux, J. ; Savéant, J-M. The Role of Homolytic Bond Dissociation Energy in the Deprotonation of Cation Radicals. Examples in the NADH Analogues Series. J. Am. Chem. Soc. 1998, 120, 2951-2958.
(128) Borgis, D.; Hynes, J. T. Curve Crossing Formulation for Proton Transfer Reactions in Solution. J. Phys. Chem. 1996, 100, 11181128.

(129) Costentin, C.; Savéant, J-M. Why Are Proton Transfers at Carbon Slow? Self-Exchange Reactions. J. Am. Chem. Soc. 2004, $126,14787-14795$

(130). Darcy, J. W.; Kolmar, S. S.; Mayer, J. M. Transition State Asymmetry in C-H Bond Cleavage by Proton-Coupled Electron Transfer. J. Am. Chem. Soc. 2019, 141, 10777-10787.

(131) Costentin, C.; Savéant, J-M. Hydrogen and Proton Exchange at Carbon. Imbalanced Transition State and Mechanism Crossover. Chem. Sci. 2020, 11, 1006-10010.

(132) Costentin, C.; Robert, M.; Savéant, J-M. Electrochemical Concerted Proton and Electron Transfers. Potential-dependent Rate Constant, Reorganization Factors, Proton Tunneling and Isotope Effects. J. Electroanal. Chem. 2006, 588, 197-206.

(133) Costentin, C.; Robert, M.; Savéant, J-M. Adiabatic and Nonadiabatic Concerted Proton-Electron Transfers. Temperature Effects in the Oxidation of Intramolecularly Hydrogen-Bonded Phenols. J. Am. Chem. Soc. 2007, 129, 9953-9963.

(134) Costentin, C.; Robert, M.; Savéant, J-M; Teillout, A-L. Concerted Proton-Coupled Electron Transfers in Aquo/Hydroxo/Oxo Metal Complexes: Electrochemistry of $\left[\mathrm{Os}^{\mathrm{II}}(\mathrm{bpy})_{2} \mathrm{py}\left(\mathrm{OH}_{2}\right)\right]^{2+}$ in Water. Proc. Natl. Acad. Sci. USA. 2009, 106, 11829-11836.

(135) Costentin, C.; Louault, C.; Robert, M.; Savéant, J-M. The Electrochemical Approach to Concerted Proton-Electron Transfers in the Oxidation of Phenols in Water. Proc. Natl. Acad. Sci. USA. 2009, 106, 18143-18148.

(136) Bonin, J.; Costentin, C.; Louault, C.; Robert, M.; Routier, M.; Savéant, J-M. Intrinsic Reactivity and Driving Force Dependence in Concerted Proton-Electron Transfers to Water Illustrated by Phenol Oxidation. Proc. Natl. Acad. Sci. USA. 2010, 107, $3367-$ 3372.

(137) Costentin, C.; Hajj, V.; Robert, M.; Savéant, J-M.; Tard, C. Concerted Heavy-Atom Bond Cleavage and Proton and Electron Transfers Illustrated by Proton-Assisted Reductive Cleavage of an 0-0 Bond. Proc. Natl. Acad. Sci. USA. 2011, 108, 8559-8564.

(138) Savéant, J-M. Proton Relays in Molecular Catalysis of Electrochemical Reactions: Origin and Limitations of the Boosting Effect. Angew. Chem. Int. Ed. 2019, 58, 2125-2128.

(139) Costentin, C.; Drouet, S.; Passard, G. ; Robert, M. ; Savéant, JM. Proton-Coupled Electron Transfer Cleavage of Heavy-Atom Bonds in Electrocatalytic Processes. Cleavage of a C-O Bond in the Catalyzed Electrochemical Reduction of $\mathrm{CO}_{2}$. J. Am. Chem. Soc. 2013, 135, 9023-9031. 